\title{
Cloning and characterization of a sialidase from the filamentous fungus, Aspergillus fumigatus
}

\author{
Mark L. Warwas • Juliana H. F. Yeung • \\ Deepani Indurugalla • Arne Ø. Mooers • \\ Andrew J. Bennet $\cdot$ Margo M. Moore
}

Received: 16 April 2010 /Revised: 22 June 2010 / Accepted: 25 June 2010

(C) Springer Science+Business Media, LLC 2010

\begin{abstract}
A gene encoding a putative sialidase was identified in the genome of the opportunistic fungal pathogen, Aspergillus fumigatus. Computational analysis showed that this protein has Asp box and FRIP domains, it was predicted to have an extracellular localization, and a mass of $42 \mathrm{kDa}$, all of which are characteristics of sialidases. Structural modeling predicted a canonical 6bladed $\beta$-propeller structure with the model's highly conserved catalytic residues aligning well with those of an experimentally determined sialidase structure. The gene encoding the putative Af sialidase was cloned and expressed in Escherichia coli. Enzymatic characterization found that the enzyme was able to cleave the synthetic sialic acid substrate, 4-methylumbelliferyl $\alpha$-D- $N$-acetylneuraminic acid (MUN), and had a $\mathrm{pH}$ optimum of 3.5. Further kinetic characterization using 4-methylumbelliferyl $\alpha$-D- $N$-acetylneuraminylgalactopyranoside revealed that Af sialidase preferred $\alpha 2-3$-linked sialic acids over the $\alpha 2-6$ isomers. No trans-sialidase activity was detected. qPCR studies showed that exposure to MEM plus human serum induced expression. Purified Af sialidase released sialic acid from diverse substrates such as mucin, fetuin, epithelial cell glycans and colominic acid, though $A$.
\end{abstract}

Mark L. Warwas and Juliana H. F. Yeung contributed equally to this work.

M. L. Warwas · J. H. F. Yeung • A. Ø. Mooers •

M. M. Moore $(\bowtie)$

Department of Biological Sciences, Simon Fraser University,

8888 University Drive,

Burnaby, British Columbia V5A 1S6, Canada

e-mail: mmoore@sfu.ca

D. Indurugalla $\cdot$ A. J. Bennet

Department of Chemistry, Simon Fraser University, 8888 University Drive,

Burnaby, British Columbia V5A 1S6, Canada fumigatus was unable to use either sialic acid or colominic acid as a sole source of carbon. Phylogenetic analysis revealed that the fungal sialidases were more closely related to those of bacteria than to sialidases from other eukaryotes.

Keywords Sialidase $\cdot$ Sialic acid · Phylogeny $\cdot$ Fungi $\mathrm{N}$-acetylneuraminic acid · Expression

\begin{tabular}{|c|c|}
\hline $\begin{array}{l}\text { Abbreviations } \\
\text { bodipy-Lac }\end{array}$ & $\begin{array}{l}\text { 4,4-difluoro-4-bora-3a,4a-diaza-s- } \\
\text { indacene-lactose }\end{array}$ \\
\hline PCR & polymerase chain reaction \\
\hline RT & reverse transcriptase \\
\hline MEM & minimal essential media \\
\hline IPTG & isopropyl $\beta$-D-thiogalactopyranoside \\
\hline$\alpha 2-3$ SMUG & $\alpha 2-3$ isomer of 4-methylumbelliferyl \\
\hline$\alpha 2-6 \mathrm{SMUG}$ & $\begin{array}{l}\alpha \text {-D- } N \text {-acetylneuraminylgalactopyranoside } \\
\alpha 2-6 \text { isomer of 4-methylumbelliferyl } \alpha \text { - } \\
\text { D- } N \text {-acetylneuraminylgalactopyranoside }\end{array}$ \\
\hline MU & 4-methylumbelliferone \\
\hline MUN & $\begin{array}{l}\text { 4-methylumbelliferyl } \alpha \text {-D- } N \text {-acetylneura- } \\
\text { minic acid }\end{array}$ \\
\hline Ni-NTA & nickel nitrilotriacetic acid agarose \\
\hline SDS-PAGE & $\begin{array}{l}\text { sodium dodecyl sulphate polyacrylamide } \\
\text { gel electrophoresis }\end{array}$ \\
\hline LB & Luria Bertani media. \\
\hline
\end{tabular}

\section{Introduction}

Aspergillus species are saprophytic fungi that are found in soil, water and decaying organic matter. There are greater than 200 species of Aspergillus; however, only Aspergillus fumigatus, Aspergillus flavus, Aspergillus niger, Aspergillus 
nidulans and Aspergillus terreus cause invasive disease (invasive aspergillosis) in immuncompromised humans [30]. Although it is not the most prevalent Aspergillus species, A. fumigatus accounts for 53-68\% of all Aspergillus infections [51] suggesting that it possesses specific virulence factors that promote host colonization. Immunocompromised patients such as those undergoing bone marrow and solid organ transplant, patients with hematological malignancies, HIV/AIDS patients and patients with chronic granulomatous disease, are most at risk of developing invasive aspergillosis $[34,39,63]$. Antifungal drugs are used to treat invasive aspergillosis; however, the current success rate averages only $53 \%$ [22] with mortality rates ranging between $20 \%$ and $84 \%$ for hematopoetic stem cell and solid organ transplant recipients, respectively [38]. Invasive aspergillosis is now a principal cause of death in immunocompromised patients in medical centers worldwide [32]. Due to the high incidence and severity of infection and lack of adequate antifungal therapy, understanding the mechanisms underlying pathogenesis by A. fumigatus is crucial.

Infection by $A$. fumigatus occurs primarily via inhalation of airborne conidiospores (conidia). As the first step in fungal colonization is thought to be the adhesion of conidia to lung tissue, several studies have attempted to identify adhesins present on the spore surface. Work from our laboratory has shown that A. fumigatus has surface sialic acids, which may mediate adhesion to basal lamina proteins [61]. Furthermore, pathogenic species of Aspergillus were shown to have a higher density of sialic acids compared to non-pathogenic species [62]. More recently, we have demonstrated that sialoglycoconjugates on the conidial surface mediate the uptake of spores into human Type II pneumocytes and cultured murine macrophages [60]. Although no sialic acid biosynthetic genes have been identified to date in the genome sequence of Aspergillus, sialic acid biosynthesis has been reported to occur de novo [62]. An alternative pathway for sialic acid acquisition in microbes is the uptake of pre-formed sialic acid via plasma membrane permeases [58]. Sialic acids are released from available glycans by the action of sialidase enzymes ( $N$-acetylneuraminic acid hydrolase, EC 3.2.1.18); a family of exo-glycosidases that catalyze the hydrolytic cleavage of sialic acid residues in glyconjugates. Sialidases are widespread in nature and to date, they have been identified in viruses, bacteria and animals [1]. Sialidases play important roles in diverse biological processes such as lysosomal catabolism [21], muscle cell differentiation [49], cancer invasion and metastasis [35], nutrition and microbial pathogenesis [12]. Viral sialidases (neuraminidases) are important in the release of newly formed virus particles from the host cell thereby playing an important role in the life cycle of the virus [54]. In the bacterial pathogen Pseudomonas aeruginosa, sialidase was found to play a significant role in biofilm production leading pneumonia and bacteremia in a mouse model of the disease [53]. In another bacterial pathogen, Vibrio cholerae, sialidase is thought to convert complex gangliosides to $\mathrm{GM}_{1}$, the receptor for cholera toxin, thereby increasing binding of the cholera toxin to host cells expressing the receptor and contributing to the pathogenicity of this organism [19]. Finally, Streptococcus pneumoniae uses two sialidases along with other exoglycosidases to obtain carbohydrates from host glycoproteins that are utilized as carbon sources required for growth [10].

We have recently discovered a gene encoding a putative sialidase in the genome sequence of Aspergillus fumigatus Af293. Here, we report the first successful cloning and expression of a fungal sialidase. Because of the importance of sialidases in microbial pathogenesis, the specific aims of the current research were: to clone and characterize the $A$. fumigatus sialidase and assess its substrate specificity and kinetic parameters, to monitor gene expression in various growth media, to determine the substrate specificity of the purified enzyme, to determine whether sialic acids are used for nutrition in A. fumigatus, and to determine the phylogenetic relationship of this enzyme with other bacterial and animal sialidases.

\section{Experimental}

\section{Computational analyses}

A 1221 base pair gene encoding a putative sialidase was identified in the A. fumigatus Af293 genome database available at The Institute of Genomic Research (TIGR) (http://www.tigr.org) (now the J. Craig Venter Institute) using a keyword search. The intron/exon structure of the gene was determined using the program GlimmerM (http://www.tigr.org/tdb/glimmerm/glmr_form.html) optimized for A. fumigatus. The derived protein sequence was then analyzed using the programs iPSORT (http://hc. ims.u-tokyo.ac.jp/iPSORT/) [6], SignalP 3.0 server (http:// www.cbs.dtu.dk/services/SignalP/) [7] and NetNGlyc (http://www.cbs.dtu.dk/services/NetNGlyc/) to determine its localization, presence and length of signal peptide, and to identify potential N-glycosylation sites. Sequence alignments were performed using ClustalW (http://www. ebi.ac.uk/Tools/clustalw2/index.html). Finally, the derived protein sequence was submitted to the PHYRE protein homology/analogy recognition engine (Imperial College of London, http://www.sbg.bio.ic.ac.uk/phyre/) [8], to generate a tertiary structural model using the sialidase from Salmonella typhimurium (Protein Data Bank (PDB) file: 3 sil) as a template. Model quality was assessed using DeepView Swiss-PDB Viewer (http://ca.expasy.org/spdbv/) 
[20] and images prepared using the molecular visualization system, PyMol (DeLano Scientific LLC, Palo Alto, CA).

A $1,020 \mathrm{bp}$ upstream fragment of the putative sialidase was analyzed for regulatory sequences in the untranslated region both manually and with the program Match-1.0 Public, which uses a library of mononucleotide weight matrices from TRANSFAC 6.0 (http://www. gene-regulation.com) [33].

\section{Phylogenetic analysis}

The phylogeny of selected sialidases was inferred using both distance and maximum likelihood techniques in PHYLIP (Phylogeny Inference Package) version 3.67 (distributed by the author, Department of Genome Sciences, University of Washington, Seattle) [14]. Data was gathered by submitting the predicted amino acid sequence of the putative A. fumigatus sialidase to Blastp [3]. Twenty-one bacterial, fungal or vertebrate sialidases with $\mathrm{E}$ values less than $4 \mathrm{e}^{-07}$ were selected for further analysis. The sequences used were as follows: XP_001266669.1, conserved hypothetical protein [Neosartorya fischeri NRRL 181]; XP_001214142.1, predicted protein [Aspergillus terreus NIH2624]; XP_001226947.1, hypothetical protein CHGG_09020 [Chaetomium globosum CBS 148.51]; YP_001107328.1, neuraminidase [Saccharopolyspora erythraea NRRL 2338]; NP_827111.1, neuramidase [Streptomyces avermitilis MA-4680]; NP_630638.1, neuramidase (secreted protein) [Streptomyces coelicolor A3 (2)]; ZP_02071388.1, hypothetical protein BACUNI_02826 [Bacteroides uniformis ATCC 8492]; YP_213298.1, putative sialidase [Bacteroides fragilis NCTC 9343]; Q02834.1, NANH_MICVI Sialidase precursor (Neuraminidase)(Micromonospora viridifaciens); A AI52169.1, Zgc:100806 [Danio rerio]; NP_001103203.1, hypothetical protein LOC100000684 [Danio rerio 2]; ABO30984.1, Neu3.1 [Danio rerio 3]; YP_001304276.1, glycoside hydrolase family 33, candidate sialidase [Parabacteroides distasonis ATCC 8503]; YP_001138502.1, hypothetical protein cgR_1608 [Corynebacterium glutamicum R]; NP_776547.1, sialidase 3 (membrane sialidase) [Bos taurus]; XP_001366978.1, PREDICTED: similar to sialidase 3 [Monodelphis domestica](Opposum); YP_001301367.1, glycoside hydrolase family 33, candidate sialidase [Bacteroides vulgatus ATCC 8482]; Q9UQ49.1, NEUR3_HUMAN Sialidase-3 (Membrane sialidase) (Ganglioside sialidase) ( $N$-acetyl- $\alpha$ neuraminidase 3); NP 057929.1, neuraminidase 3 [Mus musculus](Mouse1); BĀE26342.1, unnamed protein product [Mus musculus](Mouse2); and NP 446462.1, neuraminidase 3 [Rattus norvegicus]. Sequences were aligned and formatted for PHYLIP analysis using Clustal X2.0. Maximum-Likelihood and Neighbour-Joining algorithms were employed using the Jones-Taylor-Thornton matrix and 100 replicates were used for bootstrapping. Unrooted bootstrap consensus trees were compiled and the output files visualized using the program, Dendroscope v1.2.4 [23]. Statistical tests of user trees were done in PHYLIP using the Kishino-Hasegawa test as implemented in proml [26].

The A. fumigatus sialidase sequence was also used to search all the predicted protein sequences for the fungi that have been sequenced or are being sequenced at the Broad Institute (http://www.broad.mit.edu/cgi-bin/annotation/fgi/ blast_page.cgi) and by the Concordia University Fungal Genomics Project (https://fungalgenomics.concordia.ca/). Codon usage was analyzed by the Graphical Codon Usage Analyzer v2, Oct 2006 [17].

\section{Reverse transcriptase polymerase chain reaction}

Reverse transcriptase polymerase chain reaction (RT-PCR) was used to assess expression of the sialidase in $A$. fumigatus. To accomplish this, DNase-free total RNA was prepared from A. fumigatus mycelia cultured at $37^{\circ} \mathrm{C}$ for $6 \mathrm{~h}$ in minimal essential medium (MEM) (Life Technologies) supplemented with $10 \%(\mathrm{v} / \mathrm{v})$ human serum (male) (Sigma) and $50 \mu \mathrm{M} \mathrm{FeCl} 3$ using the Qiagen RNeasy kit (Qiagen, Mississauga, ON) and used as the template for first strand cDNA synthesis. First strand cDNA was synthesized by adding $4.5 \mu \mathrm{g}$ RNA, 2 pmol oligo-dT primer, $10 \mathrm{mM}$ dNTPs (Fermentas, Burlington, ON), $0.1 \mathrm{M}$ DTT, 40 units RNAseOUT ribonuclease inhibitor, $4 \mu \mathrm{l}$ X first strand buffer, 200 units Superscript II RNA polymerase (Invitrogen, Burlington, $\mathrm{ON}$ ) and ribonuclease-free $\mathrm{H}_{2} \mathrm{O}$ (Ambion, Austin, TX) for a total volume of $20 \mu \mathrm{l}$. The resulting solution was incubated for $60 \mathrm{~min}$ at $42^{\circ} \mathrm{C}$. The cDNA product $(2 \mu \mathrm{l})$ was then used as a template for PCR amplification by adding it to a solution consisting of $15 \mathrm{mM}$ dNTPs, 10 pmol forward primer (5'-ATCAA CGACCCGGCC (Afsialcdna-F)) and reverse primer (5'CTAATTGTTAGGACCATTCAGGATC (Afsialcdna-R)), $50 \mathrm{mM} \mathrm{MgSO}_{4}, 5 \mu \mathrm{l}$ 10X Platinum Pfx PCR buffer, 1.25 units Platinum Pfx DNA polymerase (Invitrogen) and $\mathrm{H}_{2} \mathrm{O}$ for a total volume of $50 \mu \mathrm{l}$.

Cloning and expression of the Aspergillus fumigatus sialidase in Escherichia coli

Standard molecular biology methods were performed as described by [48]. Plasmids were prepared using the Plasmid Mini kit according to the manufacturer's directions (Qiagen). Genomic DNA was obtained from A. fumigatus strain ATCC 13073 mycelia grown overnight in MYPD liquid broth $(0.3 \%, \mathrm{w} / \mathrm{v}$, yeast extract and malt extract; $0.5 \%$, w/v, peptone; and $1 \%, \mathrm{w} / \mathrm{v}$, glucose) using the phenol/chloroform method and was used as a template for 
polymerase chain reaction amplification of the putative sialidase gene. PCR amplification of the putative sialidase gene was accomplished using the following PCR reagents: 15 pmol forward and reverse primers, $10 \mathrm{mM}$ dNTPs, 2.5 units Taq DNA polymerase (Fermentas), $2 \mu \mathrm{g}$ A. fumigatus genomic DNA, 4\% DMSO, $5 \mu 1$ 10X Taq buffer and $\mathrm{H}_{2} \mathrm{O}$ for a total volume of $50 \mu \mathrm{l}$. Forward (5'-GGCATTACGG CTAGCATCAACGACCCGGCC (Afsial-F)) and reverse (5'-TACGCACCAGCGGCCGCCTAATTGTTAGG ACCATTCAGGATC (Afsial-R)) primers (Invitrogen) were designed to amplify a fragment beginning 60 base pairs downstream of the transcription start site (to prevent amplification of the predicted signal peptide) and ending at the stop codon and included NheI and NotI restriction enzyme recognition sites (underlined) to facilitate cloning into the protein expression vector pET28A + (EMD Chemicals Inc., San Diego, CA). Following PCR amplification, the entire reaction volume was run on an agarose gel and the correct PCR product was excised and purified using the Qiaquick gel extraction kit (Qiagen).

The PCR-amplified sialidase gene was treated with restriction enzymes (NheI/NotI (Fermentas)) and ligated (with the addition of 5\% DMSO to the ligation reaction) into the NheI/NotI site of pET28A+, in-frame with an Nterminal $6 \mathrm{XHis}$ tag creating the plasmid, pAfsialidase. The recombinant plasmid was used to transform Escherichia coli DH5 $\alpha$ (Life Technologies, Gaithersburg, MD) on LuriaBertani (LB) media supplemented with kanamycin $\left(30 \mu \mathrm{ml}^{-1}\right.$ ) (BioShop Canada Inc., Burlington, ON) and kanamycin-resistant transformants screened for the presence of pAfsialidase by colony PCR using primers targeting the $\mathrm{T} 7$ promoter and terminator (Invitrogen), which flank the multiple cloning site of pET28A+. Correct gene amplification and insertion was verified in several clones by restriction analysis and DNA sequencing (Macrogen, Korea).

pAfsialidase containing a complete and correct in-frame sequence of the putative sialidase was isolated from the appropriate clones and used to transform the protein expression host E. coli Tuner (DE3) (EMD Chemicals Inc.). Protein expression in transformed host cells was accomplished by culturing E.coli Tuner (DE3) in $250 \mathrm{ml}$ LB-kanamycin broth at $37^{\circ} \mathrm{C}$ with shaking at $200 \mathrm{rpm}$ to an $\mathrm{OD}_{600}$ of 0.8 . This was followed by inducing protein expression with isopropyl $\beta$-D-thiogalactopyranoside (IPTG) (BioShop Canada Inc.) at concentrations of $0.2 \mathrm{mM}, 0.4 \mathrm{mM}$, or $1 \mathrm{mM}$ at room temperature, $30^{\circ} \mathrm{C}$ or $37^{\circ} \mathrm{C}$ with shaking at $200 \mathrm{rpm}$ for 6 or $24 \mathrm{~h}$. Protein concentration was determined using the method of [9].

\section{Protein purification}

After protein induction, bacterial cells containing the expressed sialidase were cooled on ice and pelleted by centrifugation at $3,000 \mathrm{~g}$ for $20 \mathrm{~min}$ at $4^{\circ} \mathrm{C}$. The pelleted cells were then resuspended in lysis buffer $(50 \mathrm{mM}$ Tris$\mathrm{HCl}, 100 \mathrm{mM} \mathrm{NaCl}, 10 \mathrm{mM}$ imidazole, $\mathrm{pH} 8.0$ ) at $2 \mathrm{ml} / \mathrm{gram}$ bacterial pellet (wet weight). Lysozyme $\left(1 \mathrm{mg} \mathrm{ml}^{-1}\right.$ ) (BioShop Canada Inc.) was added to the bacterial suspension, which was then incubated on ice for $30 \mathrm{~min}$. Following lysozyme treatment, the suspension was sonicated with four 10-second bursts at $200 \mathrm{~W}$ with $1 \mathrm{~min}$ cooling periods between bursts. The lysate was then centrifuged at $18,000 \mathrm{~g}$ for $30 \mathrm{~min}$ at $4^{\circ}$ $\mathrm{C}$ to clear cellular debris. The cleared lysate containing the expressed 6XHis-tagged sialidase was added to $1 \mathrm{ml}$ nickel nitrilotriacetic acid agarose (Ni-NTA) (Qiagen) equilibrated with lysis buffer and allowed to bind while shaking on a rotary shaker for $60 \mathrm{~min}$ at $4^{\circ} \mathrm{C}$. Following binding, bound sialidase was eluted from Ni-NTA beads by batch purification; the bound beads were washed with $5 \mathrm{~mL}$ of wash buffer \#1 (50 mM Tris-HCl, $100 \mathrm{mM} \mathrm{NaCl}, 20 \mathrm{mM}$ imidazole, $\mathrm{pH} 8.0$ ) twice and $5 \mathrm{~mL}$ of wash buffer \#2 $(50 \mathrm{mM}$ Tris-HCl, $100 \mathrm{mM} \mathrm{NaCl}, 50 \mathrm{mM}$ imidazole, $\mathrm{pH} 8.0$ ) once, with each wash followed by centrifugation at $800 \mathrm{~g}$ for $3 \mathrm{~min}$ at $4^{\circ} \mathrm{C}$. Sialidase is eluted in $5 \mathrm{ml}$ elution buffer ( $50 \mathrm{mM}$ Tris- $\mathrm{HCl}, 100 \mathrm{mM} \mathrm{NaCl}, 250 \mathrm{mM}$ imidazole, $\mathrm{pH} 8.0$ ), followed by centrifugation at $800 \mathrm{~g}$ for $3 \mathrm{~min}$ at $4^{\circ} \mathrm{C}$, and the supernatant was collected. Residual Ni-NTA beads were removed by filtering at $4^{\circ} \mathrm{C}$. Imidazole and nonspecific proteins were removed by gel filtration chromatography (ÄTKAFPLC, GE Healthcare) with the clean-up buffer $(50 \mathrm{mM}$ Tris-HCl, $100 \mathrm{mM} \mathrm{NaCl}, \mathrm{pH} 8.0)$ at $4^{\circ} \mathrm{C}$. Fractions collected were analyzed by $12 \%$ SDS-PAGE gel. Selected fractions containing only sialidase were concentrated by loading the fraction into a 30,000 molecular weight cut-off centrifugal filter (Millipore, Billerica, MA) and centrifuging at $3,000 \mathrm{~g}$ for $30 \mathrm{~min}$ at $4^{\circ} \mathrm{C}$. The concentrated protein solution was frozen using liquid nitrogen and stored at $-80^{\circ} \mathrm{C}$.

\section{Sialidase activity assays}

The activity of enzyme preparations was determined by measuring cleavage of the synthetic sialic acid substrate, 4methylumbelliferyl $\alpha$-D- $N$-acetylneuraminic acid (MUN) (Sigma, Oakville, ON), as described previously [42]. Briefly, reactions were set up in 96-well plates by adding $200 \mu \mathrm{M}$ MUN, crude cell lysate or purified sialidase and $40 \mathrm{mM}$ sodium formate, $\mathrm{pH} 3.5$ for a total volume of $100 \mu$ l. Plates were incubated at $37^{\circ} \mathrm{C}$ for $15 \mathrm{~min}$ followed by the addition of $200 \mu \mathrm{l}$ cold stop solution $(0.1 \mathrm{M}$ glycine, $0.014 \mathrm{M} \mathrm{NaCl}, 25 \%$ ethanol, $\mathrm{pH}$ 10.7). Following the addition of stop solution, the amount of 4-methylumbelliferone released from MUN was determined using a Cary Eclipse fluorescence spectrophotometer at excitation and emission wavelengths of 365 and $450 \mathrm{~nm}$, respectively. Fluorescence produced during the course of the reaction was related to the 
concentration of MUN cleaved using a standard curve of 4-methylumbelliferone (Sigma).

To determine the A. fumigatus sialidase activity on biological substrates, the sialidase was incubated with either heat-inactivated A549 cells (a human Type II pneumocyte cell line) (ATCC), bovine mucin (Sigma), colominic acid (Sigma), fetuin (Sigma), and asialofetuin (Sigma) for $3 \mathrm{~h}$ in $40 \mathrm{mM}$ sodium formate, $\mathrm{pH} 3.5$, or in $16 \mathrm{mM}$ sodium tartrate, $\mathrm{pH}$ 5.2. To quantify the amount of sialic acid released, the method described by Kolisis [27] and Simpson et al. [52] were used with some modifications and adapted for 96 well plates. The amount sialic acid released from each sialidase reaction was tested in triplicate and each test consisted of $90 \mu \mathrm{L}$ of sample $(0.5 \mathrm{mg} / \mathrm{ml}$ for each substrate except A549 cells, which were used at a concentration of $6.4 \times 10^{5}$ cells/reaction), $1 \mathrm{M}$ Tris-HCl, $0.4 \mathrm{mM}$ NADH, 0.1 units sialic acid aldolase, and 0.2 units lactate dehydrogenase (LDH). Prior to the addition sialic acid aldolase and $\mathrm{LDH}$, the initial $\mathrm{A}_{340}$ was recorded spectrophotometrically. The tests were incubated for $1 \mathrm{~h}$ at $37^{\circ} \mathrm{C}$ and the final $\mathrm{A}_{340}$ was recorded. Quantification of the total sialic acid released was calculated as described by Kolisis [27].

$\mathrm{pH}$ rate profile

Optimal $\mathrm{pH}$ of the purified enzyme was determined by measuring the specific activity of the sialidase towards MUN in buffers of varying $\mathrm{pH}$. Buffers used were $40 \mathrm{mM}$ sodium formate $(\mathrm{pH} 3-3.5), 50 \mathrm{mM}$ sodium acetate $(\mathrm{pH} 4-5.5)$ and $32.5 \mathrm{mM}$ 2-( $N$-morpholino)ethanesulfonic acid $(\mathrm{pH} 6)$ (Sigma). The ionic strength of all buffers was maintained at $100 \mathrm{mM}$ with $\mathrm{NaCl}$ and all buffers were prepared for use at $37^{\circ} \mathrm{C}$.

\section{Quantitative RT-PCR}

Total RNA was obtained from A. fumigatus grown in MYPD for $24 \mathrm{~h}$, two chemically defined media (Kafer's and Neilands') for $24 \mathrm{~h}$, and MEM $+10 \%$ human serum (Sigma) for $2 \mathrm{~h}, 4 \mathrm{~h}, 6 \mathrm{~h}$, and $24 \mathrm{~h}$ at $37^{\circ} \mathrm{C}$. RNA samples were isolated using the RNeasy Plant RNA minikit (QIAGEN) and quantified via the NanoDrop ND-1000 Spectrophotometer. To remove any possible genomic DNA contamination, RNA used for cDNA first-strand synthesis was treated with DNase1 (Fermentas). Total first-strand cDNA was made using qScript cDNA Supermix (Quanta Bioscience) with random primers. $\beta$-tubulin forward primer (5'-TTC CGC AAT GGA CGT TAC CT) and reverse primer (5'-ACA GAG CGG TCT GGA TCT TCT), and sialidase forward primer (5'-CGG ACG CGA AGA AGT TCA AC) and reverse primer (5'-TGC CAG TGC CAT CAT TGA AG) (Invitrogen) were designed to amplify
$148 \mathrm{bp}$ and $153 \mathrm{bp}$ fragments, respectively. The expected qPCR products were blasted against the A. fumigatus genome and other fungal genomes using WU-Blast2 (www. yeastgenome.org) to ensure sequence specificity. Quantitative real-time PCR (qPCR) was completed by using PerfeCTa SYBR Green SuperMix (Quanta Bioscience). To validate the use of the $2^{-\Delta \Delta C T}$ method [31], an efficiency test was completed by performing qPCR on a dilution series of cDNA from A. fumigatus grown in MYPD at $37^{\circ} \mathrm{C}$ for $24 \mathrm{~h}$. The $\Delta \mathrm{C}_{\mathrm{T}}\left(\mathrm{C}_{\mathrm{T}}\right.$ sialidase $-\mathrm{C}_{\mathrm{T}} \beta$-tubulin) was calculated for each cDNA dilution. A plot of the log cDNA dilution versus $\Delta \mathrm{CT}$ was made and the absolute value of the slope was less than 1 (data not shown). This indicated that the efficiencies of the target and reference genes were similar and $\Delta \Delta \mathrm{CT}$ calculation for the relative quantification of the sialidase gene could be used.

\section{Kinetic analyses}

Michaelis-Menten parameters were measured using MUN and an $\alpha 2-3$ isomer of 4-methylumbelliferyl $\alpha-\mathrm{D}-N$ acetylneuraminylgalactopyranoside $(\alpha 2-3 \mathrm{SMUG})$ [25]. Each $400 \mu 1$ reaction was performed at $37^{\circ} \mathrm{C}$ by equilibrating the buffer, substrate (and for the $\alpha 2$-3SMUG kinetic determination, Aspergillus oryzae galactosidase (Sigma)) for $5 \mathrm{~min}$ in a heat block prior to addition of $9.6 \mu \mathrm{g}$ purified sialidase. The progress of the reaction was continuously monitored for 10-15 min using a Cary Eclipse fluorescence spectrophotometer equipped with a Peltier temperature controller set to $37^{\circ} \mathrm{C}$ and excitation and emission wavelengths of 365 and $450 \mathrm{~nm}$, respectively. For MUN, kinetic parameters were determined from 21 initial rate measurements using a substrate concentration range of $500 \mu \mathrm{M}$ to $4000 \mu \mathrm{M}$. For $\alpha 2-3 \mathrm{SMUG}$, kinetic parameters were determined from 5 initial rate measurements using a substrate concentration range of $250 \mu \mathrm{M}$ to $4000 \mu \mathrm{M}$. The rate versus substrate concentration data were fitted to the MichaelisMenten equation using GraphPad (GraphPad Software Inc., San Diego, CA).

\section{Trans-sialidase activity assay}

The assay used to detect possible trans-sialidase activity was previously described in [2] and its supplementary materials. Briefly, A. fumigatus sialidase $(45 \mu \mathrm{g})$ or Trypanosoma cruzi trans-sialidase $(0.6 \mu \mathrm{g})$ were incubated with either MUN (Rose Scientific) alone, or MUN and bodipy-lactose in $100 \mu \mathrm{l}$ of buffered solution for $30 \mathrm{~s}$. The products were analyzed by thin layer chromatography using an ethyl-acetate/methanol $/ \mathrm{H}_{2} \mathrm{O}(7: 2: 1 \mathrm{v} / \mathrm{v})$ solvent system and visualized under UV light at $350 \mathrm{~nm}$. The image of the TLC was captured with a PowerShot A720IS digital camera (Canon). 
Preferred carbon source utilization of A. fumigatus

To determine the preferred carbon source use by $A$. fumigatus, $10^{6} \mathrm{~A}$. fumigatus spores were inoculated per well in 96-well plates containing chemically defined media with either glucose, colominic acid, or sialic acid as a carbon source, or no carbon source. All carbon sources were tested in triplicate. Media were adjusted to $\sim \mathrm{pH} 6$ using $\mathrm{K}_{2} \mathrm{HPO}_{4}$ prior to inoculation. A parafilm overlay was added to each well to prevent cross contamination of spores from the different wells of the plate. Plates were placed in a moist chamber and incubated at $37^{\circ} \mathrm{C}$. Growth of the fungus was monitored spectrophotometrically at $\mathrm{A}_{620 \mathrm{~nm}}$.

Sialic acid detection by lectin binding

A. fumigatus conidia were inoculated into minimal media and grown for two weeks at $37^{\circ} \mathrm{C}$. During the two-week period, the cultures were replaced with fresh media every three days by first centrifuging the cultures, removing the supernatant and resuspending the mycelia in fresh minimal media. Spores were also inoculated into MYPD broth and incubated for $24 \mathrm{~h}$ at $37^{\circ} \mathrm{C}$. At the end of the incubation period, mycelia were harvested by filtration, washed and incubated with the sialic acid-specific lectin, Limax flavus agglutinin (LFA) conjugated to Texas Red (EY Laboratories) as described previously by [62]. Controls were incubated in the same way except that the LFA was omitted from the incubation. Fungi were viewed under 400X magnification with a fluorescence microscope (Zeiss) equipped with an LED lightsource (Colibri) with an excitation wavelength of $590 \mathrm{~nm}$. Images were captured with the Zeiss Axiocam MRm.

\section{Results}

Computational analyses

Analysis of the intron/exon structure of the putative sialidase gene using GlimmerM revealed no potential introns in this sialidase. Examination of the amino acid sequence revealed that the sialidase has the canonical FRIP sequence at the Nterminal region, one Asp box (SXDXGXXT/W) and a predicted mass of $42 \mathrm{kDa}$. Further analysis of the protein sequence with iPSORT, SignalP and NetNGlyc revealed that this putative sialidase has an extracellular localization, a 20 amino acid signal peptide and one low scoring $\mathrm{N}$ glycosylation site at Asn 215. The protein sequence (without the 20 amino acid signal peptide) was then submitted to the PHYRE protein homology/analogy recognition engine to generate a three dimensional model of this sialidase using the sialidase from S. typhimurium as a template. The model generated displayed the canonical 6-bladed $\beta$-propeller structure consistent with sialidases. Moreover, structural alignment using the sialidases from S. typhimurium and $M$. viridifaciens as templates resulted in good overall structural homology with root mean square deviations of only $0.58 \AA$ and $1.42 \AA$, respectively. An analysis of the Ramachandran plot of the model revealed that only 8 amino acids fell out of the allowed range of phi and psi angles (data not shown). Finally, structural and sequence alignments of the model with other bacterial and animal sialidases showed that catalytic amino acids Asp 92, Glu 260 and Tyr 370 (M. viridifaciens numbering) as well as the highly conserved arginine triad of the model align well with those of other sialidases (Fig. 1).

Regulatory sequences were identified in the promoter sequence of the A. fumigatus sialidase (Fig. 2). The eukaryotic consensus sequence GGNCAATCT (GGCCAATCT) is located 669 bp upstream of a TATAAA box. Analysis by the Match1.0 program also revealed a STRE motif (AGGGGA) 62 bp upstream of the CAAT box. STRE has been shown to bind $\mathrm{C} 2 \mathrm{H} 2$ transcription factors that regulate gene expression in response to stress [50]. The STRE-binding transcription factor Seb1 is a $\mathrm{C} 2 \mathrm{H} 2$ transcription factor in filamentous fungi that regulates response to osmotic stress [41]. A Seb1-like transcription factor has been identified in the genome sequence of $A$. fumigatus suggesting that the sialidase may be upregulated under stress.

Finally, a single GATA element was found in the upstream region of the sialidase. Trans-acting zinc-finger DNA binding proteins (the GATA proteins) regulate gene expression by binding to these elements in responsive genes; however, binding is significantly weaker when only one GATA element is present [15] suggesting that this element may have only a minor role in controlling gene expression.

Gene expression, sialidase cloning and protein expression

RT-PCR was used to determine whether the putative sialidase gene in A. fumigatus was expressed. Using a total RNA extract as a template, RT-PCR amplified an 1,161 bp cDNA product consistent with the expected size of the A. fumigatus cDNA product thus providing evidence that this sialidase is expressed in A. fumigatus (Fig. 3a). To amplify the $A$. fumigatus sialidase gene for cloning into a protein expression vector, primers were designed to amplify the gene beginning 60 base pairs downstream of the gene start site to avoid amplification of the signal peptide, which, along with the $\mathrm{N}$-terminal 6XHis tag, may have been cleaved after extracellular secretion by the protein expression host. The amplified fragment was cloned into pET28A+, which was used to transform E. coli DH5 $\alpha$ (Fig. 3b). Restriction digest and sequencing were used to verify correct amplification and 

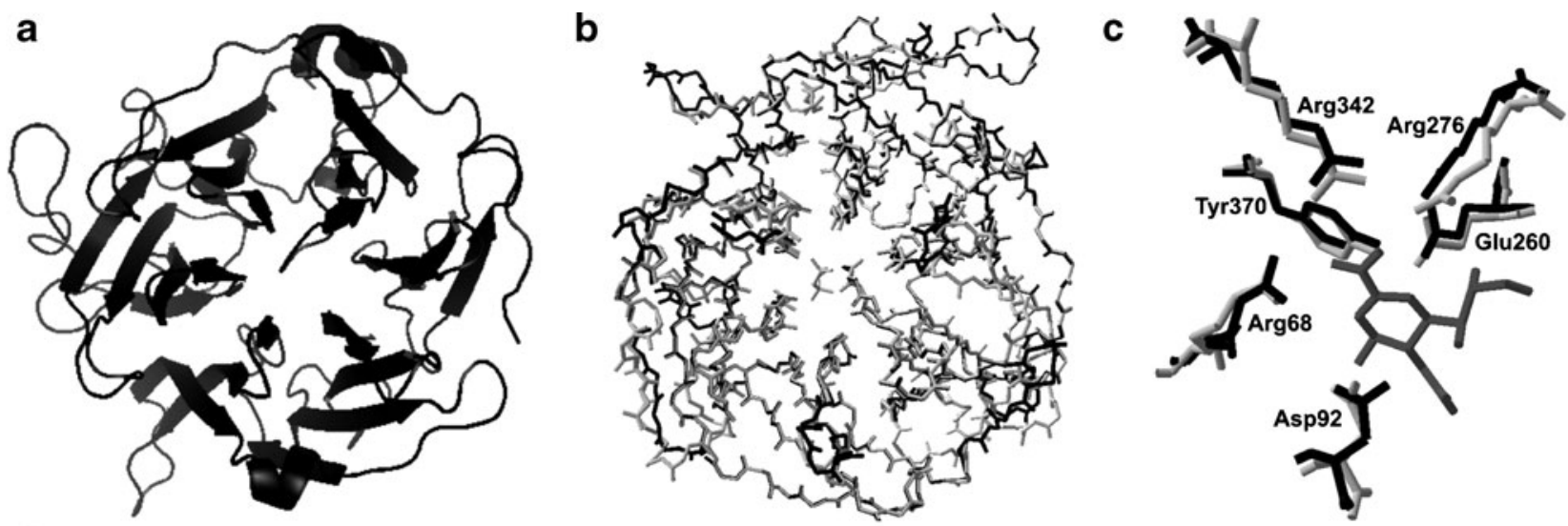

d

$*$

Af HSFRIP AVVRTTTGRILAFAEGRRHTNQDF-GDINLVYKRTKTTANHGASP SDWEP---LREVVG-----SGAGTWGNPTPVVDDDNTIYLFLSWNGATYSQN 149 MV PHYRIPALTVTPDGDLLASYDGRP-TGIDAPGPHSILQRRSTDGGR------TWGE---QQVVS-AGQTTAPIKGFSDP SYLVDRETGTIFNFHVYSQRQGFA 156 Dr VTYRIP ALIYNGENKTFLAF AEKRKTTDDTDADVLVMRRG IWRDG-----VVEWDMTHECLS-----S ASLPNHRSMIPCP VYERE SKTLFLFF ITVPVG VSE 122 Bt VTYRIPALIYVPPAHTFLAFAEKRS SSKDDALHLVLRRGLRTGQ-----SVQWEP-LKSLM-----KATLPGHRTMNPCP VWERKSGYVYLFFICVQGHVTE 113 HS ITYRIP ALLYIPPTHTFLAF AEKRSTRRDEDALHLVLRRGLRIGQ-----LVQWGP-LKPLM-----EATLPGHRTMIPCP VWEQKSGCVFLFFICVRGHVTE 113 Rn ITYRIP ALLYIPPTHTFLAFAEMRTS SRDEDAVYLVFRRG VMKGC-----S VEWGP-QQPLM-----EATLPGHRTMSPCP VWEKNTGRVYLFFICVQGHVSE 113 Mm VTYRIPALLYLPPTHTFLAFAEKRTSVRDEDAACLVLRRGLMKGR-----SVQWGP-QRLLM-----EATLPGHRTMNPCP VWEKNTGRVYLFFICVRGHVTE 112

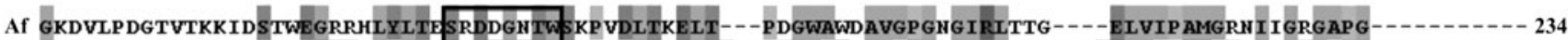
MV G------SPPGTDP ADP NVLHANVAT STDGGLTWSHRT-ITADITP--DPGWRSRFAASGEG IQLRYGPHAGRLIQQYTI INAAGAFQAV--------- 237 Dr HK----------QIKENKNQARLCY IT SKDTGKTWSAVTDLTADVIGEQEKNWATFAVGPGHG IQMK-----SGRLI IP AYTYYFTSGTSPT------- SHAF 203

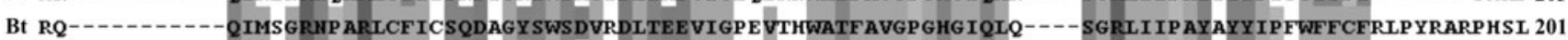
HS RQ--------QIVSGRNAARLCFIY SQDAGCSWSE VRDLTEEVIG SELKHWATFAVGPGHG IQLQ----SGRLVIP AYTYYIP SWFFCFQLPCKTRPHSL 201 Rn RW-------QLLWGRAAARLCFLY SEDSGCSWGE VKDLTEEVVG SEMKHWATFAVGPGHG IQLQ----SGRLLIP AYAYLISCWFLCF--PCS VKPHSL 199 Mm RC----------QI VWGKNAARLCFLCSEDAGCSWGE VKDLTEEVIGSEVKRWATFAVGPGHGIQLH----SGRLI IP AYAYYVSRWFLCF--ACS VKPHSL 199 $*$

Af ------HRTWS $Q$ QRLSG----AGAEGTIVQTPDGKLYRNDRP SQR---GYRMVARGTL---EGFGAFAPDAGLPDP-ACQGSVLRYNMV SVYSDDHGRTWRAGEAVG---VGMDENKTVELSDGRVLLNSRDSA--RSGYRKVAVSTDGGHS YGPVTIDR-DLPDP-THNASI IRAFPD------- - - - 320

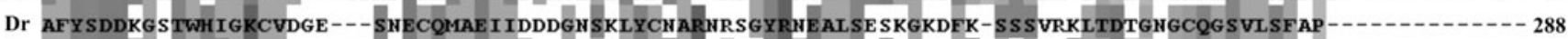
BT MIYSDDLGATWHHGRLIKPMV--TVECEVAEVIGKAGHPVLYCSARTPNRHRAEALSIDHGECFQKPVLSHQLCEPPHGCQGSVVSFCPLE IPGGCQDLAGED 302 HS MIY SDDLGVTWHHGRLIPPMV--TVECEVAEVTGRAGHPVLYCSARTPNRCRAEALSTDHGEGFQRLAL SRQLCEPPHGCQG SVVSFRPLE IPHRCQDS S SKD 302 Rn MFY SDDLGVTWHCGKFIKPQV--TGECQVAEVPGKAGNLVLYCS ARTPNKFRAEAF STDS GDCFQKPTLNQQLCEPRGGCQG SVVSTRPLKMPYTCQDS SGKD 300 Mm MIYSDDFGVIWHHGKFIEPQV--TGECQVAEVAGTAGNPVLYCSARTP SRFRAEAFSTDSGGCFQKPTLNPQLHEPRTGCQGSVVSFRPLKMPNTYQDS IGKG 300

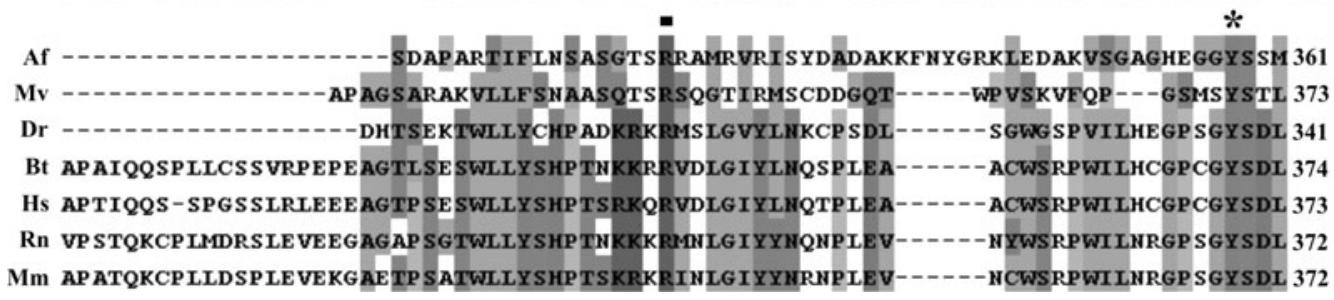

Fig. 1 Structural modeling and sequence alignment of the $A$. fumigatus sialidase. a The putative sialidase was predicted by PHYRE to fold into a 6-bladed $\beta$-propeller. b Structural superposition of the putative A. fumigatus sialidase (black) on the sialidase from $M$. viridifaciens (grey) (PDB: 1eus). c Superposition of the A. fumigatus model active site onto that of $M$. viridifaciens. It can be seen that catalytic residues (Asp 92, Glu 260 and Tyr 370) as well as the arginine triad (Arg 68, Arg 276 and Arg 342) (M. viridifaciens

insertion of the gene into pET28A + (data not shown). Sequencing revealed a single synonymous base difference $\mathrm{T}_{996}$ to $\mathrm{C}_{996}$ (maintaining an aspartic acid at this position) between the cloned gene and the gene sequence available for numbering) align well with those of the A. fumigatus sialidase model. d) Sequence alignment of the A. fumigatus sialidase with sialidases from M. viridifaciens (Mv), Danio rerio (Dr), Bos taurus (Bt), Homo sapiens (Hs), Rattus norvegicus (Rn) and Mus musculus (Mm). Catalytic residues (Asp 92, Glu 260 and Tyr 370), marked with *,

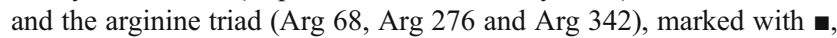
are well conserved among these sialidases. The conserved Asp box (SXDXGXT) is outlined

strain 293 in the A. fumigatus genome database. The recombinant plasmid was then used to transform the protein expression host, E. coli Tuner. Successful transformation was detected by colony PCR (data not shown) and by monitoring 
Fig. 2 Promoter sequence of the putative A. fumigatus sialidase. A 978 bp upstream sequence revealed the presence of eukaryotic promoter elements (caat and tata boxes) as well as the STRE motif (agggga) found in many fungi. A single gata sequence was identified in the upstream sequence that may act as a weak binding site for gata transcription factors tctggcgaggaatcttgtgcttcatgtcatgcctagctcaagaagtcccccagaactgcc ctttccctctacttctcgtctgagtctctacgtacactcaagagttgagtcctgatttg ctggtacaactggaatcaatgctacgggaacacttgggatgattggcactcgtgcctag acagagattagccalaggggaacctgaccacgcaatatgtcgtgacgatgtccctggttgc tcgactcgcattttgtgoccatctctggaagacttatgtgcttggcaagggattctcgga atgctcaggtgaatgacttcagggggtttcttcatcagtcatcaccagcaatgctgtaag tcgaggcactgggctatcctgaccaagagcagatgtgcttgaaccaccgacaacgggagt gcttcaagtcggggctgtatagcagacgacagttgcagtgttcgtgaccttcgtgacct cgtgactgattcaatgtatatccttggcagactcgcagcacccgtccggctccacctgta agtoaccttcctgcagtattgtctcctgcagtagacatgtcggacatccttactacccct ggctgcaaggagctaccataagcccgttcgtgcattttgaaggcaaggattatgcacacg agcgggatgggtagtcagcgatgcatact tcattatcgtactgccagaaggcaggctgat cagcttacaagacggtcggtctaattccoagtcgtattcgctagtctgtgcttgtcte ggtaaatactggcotgcatgttgatcgtatacgaggtctgtcgoatcaacacoaggttat attaagtagctgcaacacaagcccacgtgcgtccatattcaacaatgtctggataactca

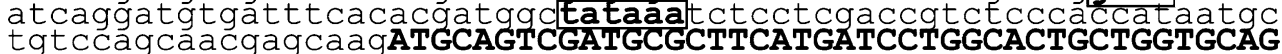
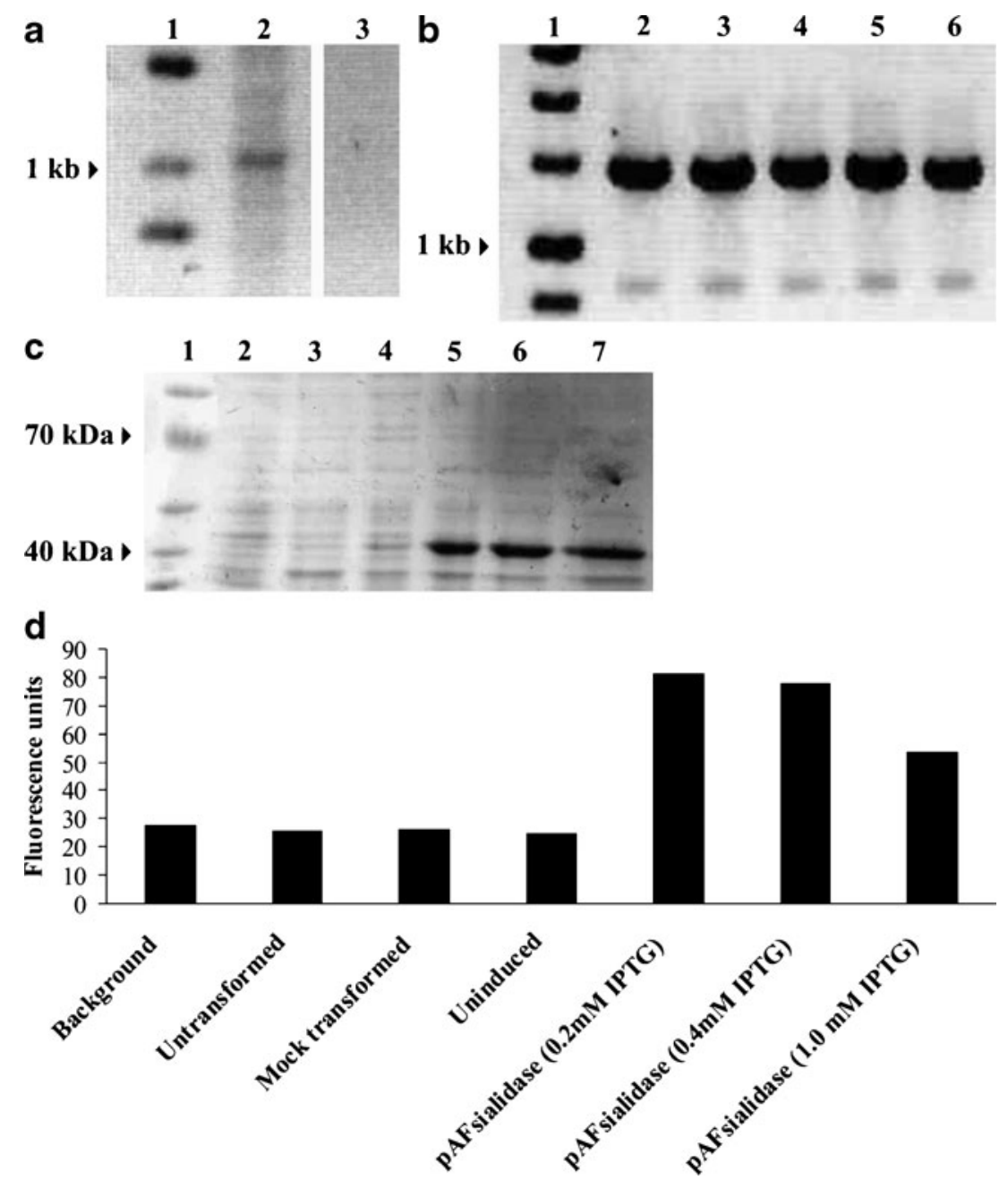

Fig. 3 pAfsialidase transformed E. coli Tuner expresses an active sialidase. a RT-PCR using total RNA from A. fumigatus as a template yields an 1,161 bp cDNA band consistent with the sialidase gene product indicating the sialidase is expressed in A. fumigatus under experimental conditions. Lane 1 represents the DNA ladder, lane 2 is the $A$. fumigatus sialidase RT-PCR product and lane 3 is the negative RT-PCR control. b Colony PCR of transformed E. coli yields a $1,475 \mathrm{bp}$ band (1,161 bp (sialidase gene) $+314 \mathrm{bp}$ (flanking region)) showing that the A. fumigatus sialidase gene is successfully cloned into the pET28A + protein expression vector. Lane 1 represents the DNA ladder and lanes 2-6 are the colony PCR products of the 5 selected kanamycin-resistant clones. c Transformation of the E. coli
Tuner protein expression strain with pAfsialidase and induction by IPTG $(0.2 \mathrm{mM}-1.0 \mathrm{mM})$ produced a $42 \mathrm{kDa}$ band consistent with the predicted mass of the A. fumigatus sialidase. Lane 1 represents the protein ladder, lane 2 is the lysate from untransformed E. coli Tuner, lane 3 is the lysate from mock (pET28A+) transformed cells, lane 4 is the lysate from transformed but uninduced cells and lanes 5-7 represent cell lysates from Tuner transformed with pAfsialidase and induced with varying concentrations of IPTG. d Crude bacterial cell lysates transformed with pAfsialidase and induced with IPTG have activity toward the synthetic sialic acid substrate, MUN. Importantly, untransformed, mock transformed and uninduced E. coli Tuner controls do not express a $42 \mathrm{kDa}$ band or have activity toward MUN 


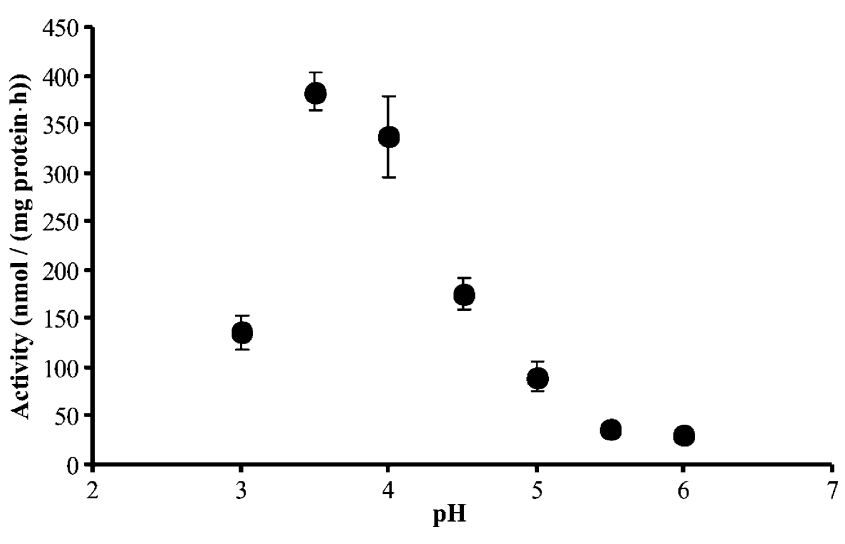

Fig. 4 The purified A. fumigatus sialidase has a pH optimum of 3.5. To measure the optimum $\mathrm{pH}$ of the sialidase, activity toward MUN was determined at $37^{\circ} \mathrm{C}$ in buffers ranging in $\mathrm{pH}$ from 3-6. Buffers used were $40 \mathrm{mM}$ sodium formate $(\mathrm{pH} 3-3.5), 50 \mathrm{mM}$ sodium acetate (pH 4-5.5) and $32.5 \mathrm{mM}$ 2-( $N$-morpholino)ethanesulfonic acid ( $\mathrm{pH} 6)$. Ionic strength of the buffers was maintained at $100 \mathrm{mM}$ with $\mathrm{NaCl}$

the expression of the putative sialidase by SDS-PAGE and by assessing the activity of the crude bacterial cell lysate toward the sialidase substrate, MUN. Transformed E. coli Tuner induced with IPTG produced a protein with a molecular mass of $42 \mathrm{kDa}$, consistent with the predicted mass of this sialidase, and the crude lysate had activity toward MUN. The protein expression and enzyme activity were solely attributable to the cloned A. fumigatus gene because untransformed, mock $(\mathrm{pET} 28 \mathrm{~A}+)$ transformed and transformed but uninduced $E$. coli Tuner crude lysates did not produce $42 \mathrm{kDa}$ bands and were not able to cleave MUN (Fig. 3c and d). Several expression conditions were assessed to maximize protein expression and enzymatic activity and it was found that inducing protein expression with $1 \mathrm{mM}$ IPTG for $24 \mathrm{~h}$ at $30^{\circ} \mathrm{C}$ was optimal (data not shown). Furthermore, the addition of bovine serum albumin, $\mathrm{CaCl}_{2}, \mathrm{MgCl}_{2}$ or $\mathrm{MnCl}_{2}$ did not increase enzyme activity in the MUN activity assay (data not shown). Finally, the optimal $\mathrm{pH}$ of this enzyme was determined using affinity purified sialidase to cleave MUN in buffers ranging in $\mathrm{pH}$ from 3 to 6 . The data obtained indicated that the A. fumigatus sialidase has a $\mathrm{pH}$ optimum of 3.5 (Fig. 4).

\section{Quantitative RT-PCR}

Table 1 contains the expression data that are the mean of triplicate runs conducted for each sample of RNA from the different growth conditions. The normalized expression level of sialidase in MYPD and in two minimal media (Kafer and Neiland) was approximately the same. In contrast, when conidia were grown in MEM plus human serum, sialidase gene expression increased 3-5 fold within the first $4 \mathrm{~h}$ of incubation, a period which corresponds to conidial swelling and germination. Thereafter, expression levels decreased almost 20-fold.

\section{Enzyme kinetics}

Michaelis-Menten kinetic parameters of the A. fumigatus sialidase were measured using MUN and an $\alpha 2-3$ isomer of 4-methylumbelliferyl- $\alpha-D-N$-acetylneuraminylgalactopyranoside as substrates [25]. The $A$. fumigatus sialidase had a $K_{\mathrm{m}}$ of $3,300 \pm 380 \mu \mathrm{M}$ and a catalytic efficiency $\left(k_{\text {cat }} / K_{\mathrm{m}}\right)$ of $22.3 \pm 3.0 \mathrm{M}^{-1} \mathrm{~s}^{-1}$ for MUN. The $\alpha 2-3$ linkage was preferentially cleaved over substrates with an $\alpha 2-6$ linkage; the A. fumigatus sialidase had a $\mathrm{K}_{\mathrm{m}}$ of $3,100 \pm 780 \mu \mathrm{M}$ and catalytic efficiency $\left(k_{\mathrm{cat}} / K_{\mathrm{m}}\right)$ of $0.144 \pm 0.001 \mathrm{M}^{-1} \mathrm{~s}^{-1}$ toward $\alpha 2-3$ SMUG (Table 2).

Table 1 Relative Aspergillus fumigatus sialidase gene expression values under different growth conditions

\begin{tabular}{lccccc}
\hline Growth condition $^{\mathrm{a}}$ & Sialidase avg. $\mathrm{C}_{\mathrm{T}}$ & $\beta$-tubulin avg. $\mathrm{C}_{\mathrm{T}}$ & $\Delta \mathrm{C}_{\mathrm{T}}{ }^{\mathrm{b}}$ & $\Delta \Delta \mathrm{C}_{\mathrm{T}}^{\mathrm{c}}$ & $\begin{array}{c}\text { Normalized sialidase amount relative } \\
\text { to } \beta \text {-tubulin (2 }\end{array}$ \\
\hline MYPD, 24 h & & 19.52 & 6.67 & 0 & $1.00(0.78-1.27)$ \\
Kafer's MM, 24 h & 26.18 & 21.73 & 6.63 & -0.03 & $1.02(0.79-1.33)$ \\
Neilands' MM, 24 h & 28.36 & 19.41 & 6.89 & 0.24 & $0.86(0.32-2.29)$ \\
MEM + human serum, 2 h & 26.31 & 26.91 & 5.12 & -1.54 & $2.93(1.75-4.93)$ \\
MEM + human serum, 4 h & 32.03 & 23.83 & 4.40 & -2.26 & $4.80(2.76-8.34)$ \\
MEM + human serum, 6 h & 31.75 & 22.22 & 9.52 & 2.87 & $0.14(0.08-0.24)$ \\
MEM + human serum, 24 h & 32.46 & 22.68 & 9.78 & 3.12 & $0.12(0.10-0.13)$ \\
\hline
\end{tabular}

${ }^{a}$ Data reported are the mean of triplicate runs conducted for each sample of RNA from the different growth conditions. $\beta$-tubulin was used as a reference gene to normalize data

${ }^{\mathbf{b}} \Delta \mathrm{C}_{\mathrm{T}}=\mathrm{C}_{\mathrm{T}}$ value of gene of interest (sialidase) $-\mathrm{C}_{\mathrm{T}}$ value of reference gene ( $\beta$-tubulin)

${ }^{\mathbf{c}} \Delta \Delta \mathrm{C}_{\mathrm{T}}=\Delta \mathrm{C}_{\mathrm{T}}$ test condition $-\Delta \mathrm{C}_{\mathrm{T}}$ calibrator condition. The calibrator condition is MYPD for $24 \mathrm{~h}$ at $37^{\circ} \mathrm{C}$

${ }^{\text {d }}$ Fold change value is calculated as $2^{-\Delta \Delta C T}$ 
Table 2 Kinetic parameters of selected sialidases

\begin{tabular}{|c|c|c|c|c|c|c|}
\hline Sialidase & Substrate & $\mathrm{K}_{\mathrm{m}}(\mu \mathrm{M})$ & $\mathrm{K}_{\text {cat }}\left(\mathrm{S}^{-1}\right)$ & $\mathrm{K}_{\mathrm{cat}} / \mathrm{K}_{\mathrm{m}}\left(\mathrm{M}^{-1} \mathrm{~s}^{-1}\right)$ & $\begin{array}{l}\text { Specific activity } \\
\left(\mathrm{nmol} \mathrm{mg} \text { protein }{ }^{-1} \mathrm{~h}^{-1}\right)\end{array}$ & References \\
\hline \multirow[t]{3}{*}{ A. fumigatus } & MUN & $3,300 \pm 380$ & $0.0743 \pm 0.0050$ & $22.3 \pm 3.0$ & $383.7 \pm 19.1^{\mathrm{a}}$ & \\
\hline & $\alpha 2-3 \mathrm{SMUG}$ & $3,100 \pm 780$ & $0.0004 \pm 0.0001$ & $0.144 \pm 0.001$ & $6.7 \pm 2.1^{\mathrm{d}}$ & current work \\
\hline & $\alpha 2-6 \mathrm{SMUG}$ & n.d. & n.d. & n.d. & $2.2 \pm 0.4^{\mathrm{d}}$ & \\
\hline HsNeu2 & MUN & 440 & & & $3,060^{\mathrm{a}, \mathrm{c}}$ & {$[37,56]$} \\
\hline Neu3 & MUN & 143 & & & $250.7^{\mathrm{a}}$ & {$[22,36]$} \\
\hline \multirow[t]{2}{*}{ C. perfringens } & MUN & $165 \pm 0.024$ & & & $1.7 \times 10^{7 \mathrm{~b}}$ & {$[28]$} \\
\hline & MUN & $35 \pm 6$ & $44.0 \pm 0.1$ & $(1.3 \pm 0.2) \times 10^{6}$ & & \\
\hline \multirow[t]{2}{*}{ M. viridifaciens } & $\alpha 2-3 \mathrm{SMUG}$ & $380 \pm 70$ & $0.20 \pm 0.02$ & $530 \pm 150$ & & {$[26]$} \\
\hline & $\alpha 2-6 \mathrm{SMUG}$ & $240 \pm 30$ & $0.069 \pm 0.003$ & $290 \pm 50$ & & \\
\hline
\end{tabular}

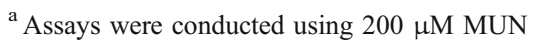

${ }^{\mathrm{b}}$ Assay was conducted using $1 \mathrm{mM}$ MUN

${ }^{\mathrm{c}}$ Enzyme expressed and purified from $\operatorname{Cos} 7$ cells

${ }^{\mathrm{d}}$ Assays were conducted using $500 \mu \mathrm{M}$ SMUG substrate

nd denotes not determined

\section{Substrate profile}

Af sialidase was able to release sialic acids from a wide variety of natural substrates including bovine salivary mucin, colominic acid (a homopolymer of sialic acid with $\alpha 2-8$ ketosidic linkages), bovine fetuin, a serum glycoprotein containing both $\alpha 2-6$ and $\alpha 2-3$-linkages in a ratio of $\sim 3: 2$, and glycoproteins and glycolipids from thermallydenatured human lung epithelial cells (A549 pneumocyte cell line, containing both $\alpha 2-3$ and $\alpha 2-6$-linkages) (Fig. 5). In both $\mathrm{pH}$ conditions, the asialofetuin control contained no released sialic acids, as expected. The substrate profiles at pH 3.5 are shown in Fig. 5. At pH 5.2, activity was higher with A549 cells and fetuin (data not shown) suggesting that, even though the enzyme activity is lower at $\mathrm{pH} 5.2$, the substrate was more accessible.

Despite the ability of the sialidase to release sialic acid from these substrates, A. fumigatus was unable to use either colominic acid or sialic acid as a sole source of carbon (data not shown).

\section{Trans-sialidase activity}

Trans-sialidase activity was not detected with the Af sialidase. Figure 6 shows that incubation of A. fumigatus sialidase with bodipy-lac, a fluorescent substrate for trans-sialylation and

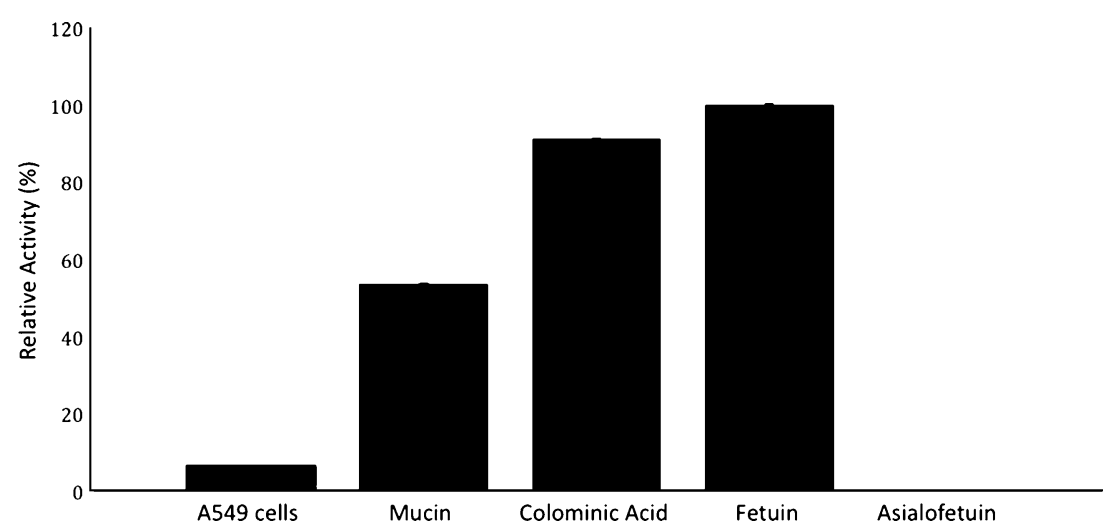

Fig. 5 Sialidase activity with sialylated substrates. Enzymatic activity of $A$. fumigatus sialidase was measured with heat-inactivated A549 cells (a human pneumocyte cell line), bovine mucin, colominic acid, fetuin, and asialofetuin. All substrates were tested at the $\mathrm{pH}$ optimum for the enzyme as described in Materials and Methods. The specific activity of each enzyme was measured against the specific activity of fetuin $(42 \mathrm{nmol} / \mathrm{mg}$ protein $/ \mathrm{hr})$ to calculate the relative activity of the enzyme towards each biological substrate 


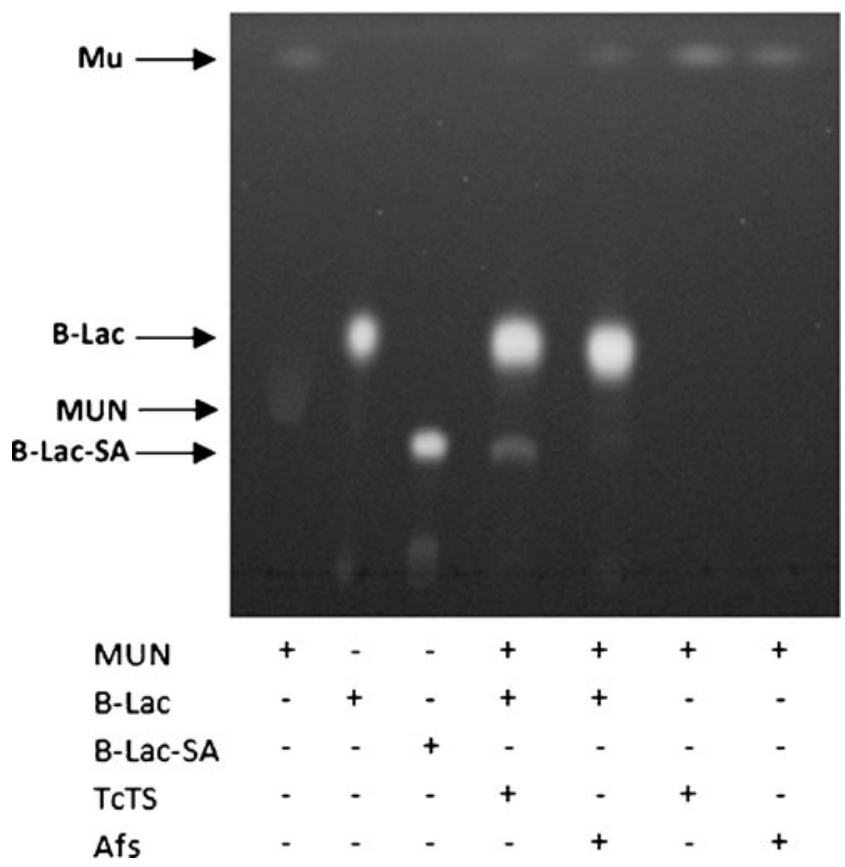

Fig. 6 Trans-sialidase activity analysis of A. fumigatus sialidase. A. fumigatus sialidase (AfS) was incubated with MUN, or with MUN and bodipy-lactose. Sialidase activity cleaves the sialic acid from MUN releasing the fluorescent product 4-methylumbelliferone (MU). Trans-sialidase activity results in the addition of sialic acid to the acceptor, bodipy-lactose (B-Lac) forming the more polar product, bodipy-lactose-sialic acid (B-Lac-SA). Recombinant T. cruzi transsialidase formed B-Lac-SA (and some MU as expected); however, no B-Lac-SA was formed by A. fumigatus sialidase. The faint band in the AfS lane that runs slightly higher than B-Lac-SA is MUN, confirmed by its purple fluorescence not evident in the black and white photo

MUN generated MU but produced no sialylated derivative (bodipy-Lac-SA). These data indicate that $A$. fumigatus sialidase was able to remove terminal Sia residues but was unable to catalyze their transfer to the acceptor substrate. The positive control, recombinant trans-sialidase from Trypanosoma cruzi, produced the bodipy-Lac-SA derivative, as expected.

De novo synthesis of sialic acids

In a previous study, we reported that A. fumigatus was able to synthesize sialic acids when grown on solid media containing no sialic acid, suggesting that sialic acid biosynthesis occurred de novo [62]. We wished to confirm this finding using synthetic liquid media to ensure that no sialylated compounds could have contributed to sialic acids in the fungus. Figures 7 and 8 show that $A$. fumigatus mycelia bind the sialic acid-specific lectin, LFA, when grown in liquid minimal medium containing only glucose as a carbon source. Similar results were obtained with growth in complex medium, MYPD. Staining intensity in MYPD was greater, confirming our previous finding that sialic acid density is enhanced when the fungus is grown in this medium [62]. Thus, de novo biosynthesis of sialic acids occurs in A. fumigatus.

Phylogenetic analysis

The phylogeny of the fungal sialidase was investigated using both Neighbour-Joining distances inferred from protdist and Maximum Likelihood analysis of protein evolution; both resulted in the same placement of the sialidase from A. fumigatus. The consensus tree generated from the maximum likelihood analysis is shown in Fig. 5. Many studies have shown that the Fungi are the sister group to animals and form part of the crown group of eukaryotes along with plants and animals [29, 59]. The four fungal species formed a separate cluster from both the animal and bacterial sialidases. The closest relative to A. fumigatus was $N$. fischeri; this reflects the known close phylogenetic relationship between these organisms [13]. However, our analyses also revealed that the fungal sialidases are more closely related to sialidases from Actinobacteria belonging to the order Actinomycetales, in particular, Streptomyces coelicolor, Streptomyces avermitilis and Saccharopolyspora erythraea. Although it is in a different genus, $S$. erythraea biology closely resembles that of these streptomycetes [24]. Interestingly, sialidases from two other Actinobacteria, M. viridifaciens and $C$. glutamicum, clustered separately with other Bacteria, the Bacteroidetes (B. vulgatus, P. distasoni, B. fragilis and B. uniformis) (Fig. 5) and the Planctomycetes (data not shown). To determine whether the data statistically supported this separation of Actinomycetales, we performed a Kishino-Hasegawa test for two trees; the original tree versus one in which the $S$. avermitilis, $S$. coelicolor and $S$. erythraea sialidases were constrained to be in a clade with $M$. viridifaciens and $C$. glutamicum. The results showed that this tree was significantly worse (Diff $\log \mathrm{L}=-12$ ) than the tree shown in Figure 5 . Consistent with the finding that the fungal sialidase has no trans-sialidase activity, the trans-sialidase protein of Trypanosoma cruzi formed a unique branch that diverged from the Bacteroides spp., distinct from the C. glutamicum/M. viridifaciens sialidases (data not shown).

Only three other species of Fungi, A. terreus, $C$. globosum and $N$. fischeri (shown on tree) gave significant blastp hits when searched against the A. fumigatus sialidase. The candidate pool included fungi being sequenced by both the Broad Institute and the Concordia University Fungal Genomics project (a total of 40 species representing zygomycetes, chytridiomycetes, ascomycetes and basidiomycetes). In addition to $N$. fischeri, the genomes of several other Aspergillus species have been 
Fig. 7 A. fumigatus was grown in minimal media where glucose was the only carbon source $\mathbf{a}-\mathbf{b}$ and in MYPD e-f. After washing, mycelia were incubated with LFA bound to Texas Red and processed for fluorescence microscopy as described in Materials and Methods. Controls were treated identically except that LFA-TR was omitted (minimal media, c-d; MYPD, g-h)
DIC
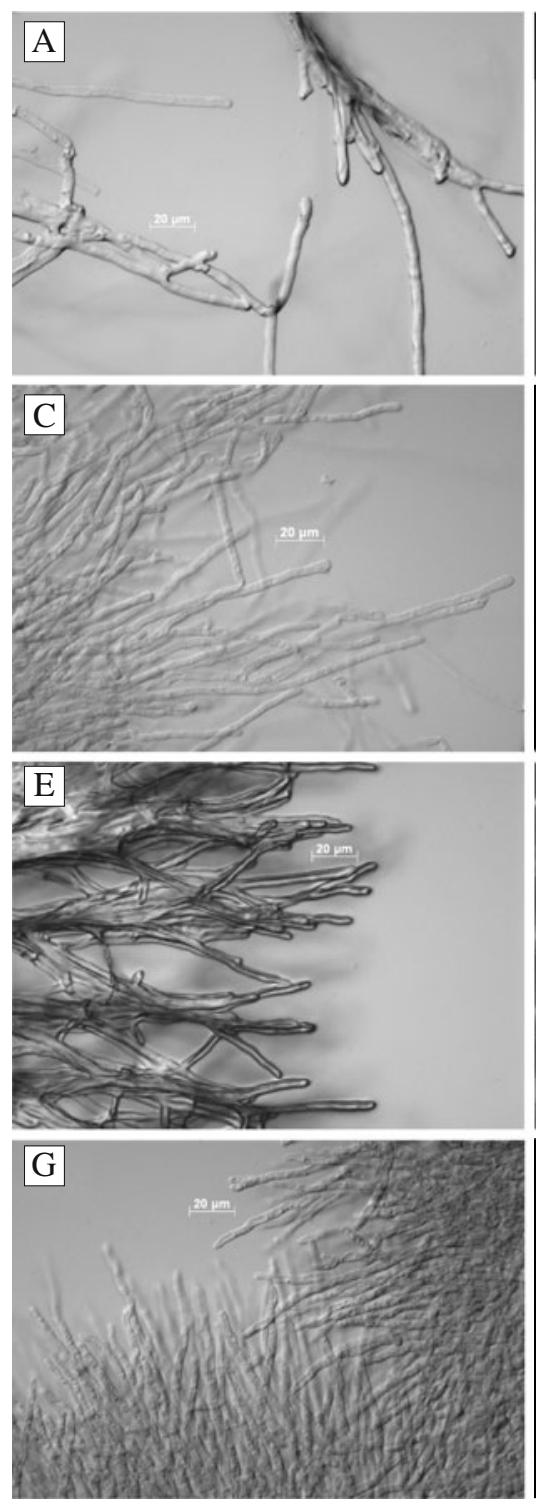

Fluorescence
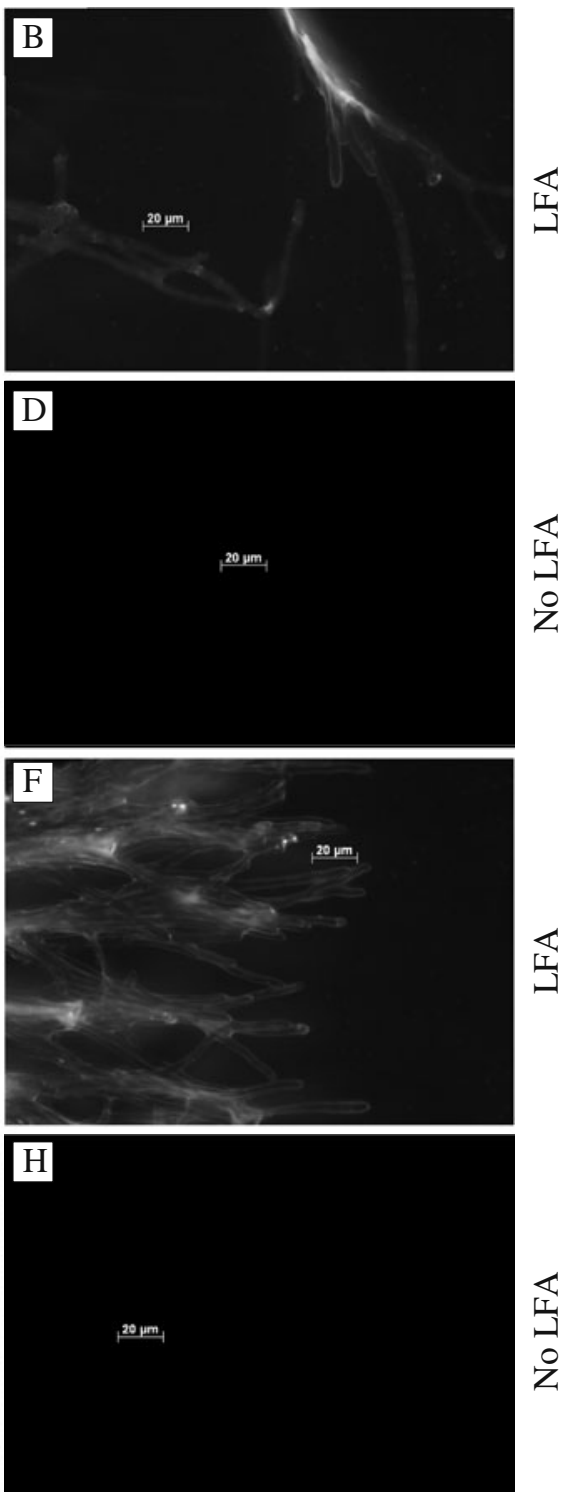

sequenced; however, other than A. terreus, we found no significant matches, including from Aspergillus nidulans (data not shown). The A. nidulans genome has two proteins that have sialidase domains and one protein has two Asp boxes. However, these genes are unlikely to encode sialidases: no FRIP sequences are present, and the top models generated by PHYRE did not align well to the M. viridifaciens sialidase as only 189 and 304 atoms were aligned in each protein (compared to thousands of atoms in the A. fumigatus sialidase) and there was no alignment of catalytic residues (data not shown). Many glycosyl hydrolases as well as other non-homologous proteins possess Asp-box repeats [11] and these sequences may encode other glycosyl hydrolases.

\section{Discussion}

We have successfully cloned and expressed a sialidase from Aspergillus fumigatus, which represents the first cloning of a fungal sialidase. Initial computational analysis indicated a protein mass of $42 \mathrm{kDa}$, the presence of conserved FRIP and Asp-box domains and folding into the canonical 6 -bladed $\beta$-propeller, characteristics which are present in all known sialidases [45]. Molecular modeling revealed that the active site of the A. fumigatus sialidase aligned well with that of the experimentally determined structure of the sialidase from the bacterium, $M$. viridifaciens (1eus). Tyr 370, Asp 92 and Glu 260 of the M. viridifaciens sialidase, which function as the nucleophile, general base and general 


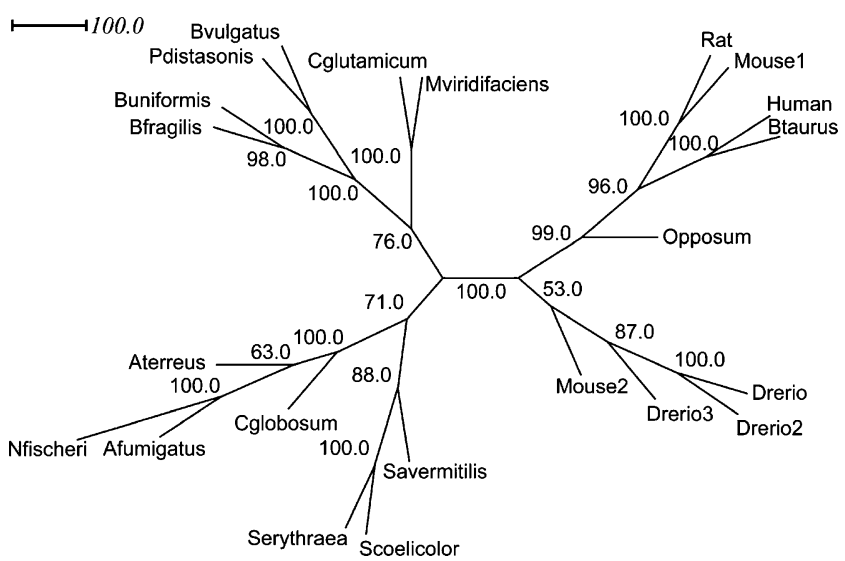

Fig. 8 Unrooted bootstrap consensus tree from maximum-likelihood analysis of the amino acid sequences of 22 sialidases from Bacteria, Animalia and Fungi. The mammalian and fish sialidases (all sequences on the right split at $100 \%$ bootstrap) form a cluster distinct from the Bacterial and Fungal sialidases. Despite the fact that Fungi are more closely related to animals than bacteria, the fungal sialidases (N. fischeri, A. fumigatus, A. terreus and C. globosum) are more closely related to a subset of bacterial sialidases from the Actinobacteria, S. avermitilis, S. erythraea and S. coelicolor

acid, respectively, correspond with Tyr 338, Asp 64 and Glu 229 of the A. fumigatus sialidase model. Furthermore, the highly conserved arginine triad, which functions to stabilize the sialic acid carboxylic acid is also conserved further supporting the quality of this model [45]. The fungal sialidase was enzymatically active when tested using standard substrates.

The kinetic parameters $K_{\mathrm{m}}$ and $k_{\mathrm{cat}}$ and specific activity of the A. fumigatus sialidase toward MUN are lower than those reported for the bacterial sialidases from $C$. perfringens and $M$. viridifaciens (Table 2) [25, 28]; however, the specific activity of the A. fumigatus sialidase is similar to that of the human ganglioside sialidase Neu3 $[21,36]$. One possible explanation for the lower activity of the fungal sialidase compared to bacterial sialidases could be that the substrate (MUN) used for these assays is not the natural substrate for this enzyme. For example, human ganglioside sialidase, Neu3, preferentially acts on the ganglioside GD1a with a lower $\mathrm{K}_{\mathrm{m}}$ value $(98 \mu \mathrm{M}$ for GD1a compared to $143 \mu \mathrm{M}$ for MUN) and a fivefold greater specific activity $\left(120 \mathrm{nmol} \mathrm{mg}\right.$ protein $^{-1} \mathrm{~h}^{-1}$ for MUN compared to $600 \mathrm{nmol} \mathrm{mg} \mathrm{protein}{ }^{-1} \mathrm{~h}^{-1}$ for GD1a) than it does for MUN [28]. Furthermore, Neu3 preferentially cleaves terminal $\alpha 2-8$-linked sialic acids from GD3 over GD1b despite their similar terminal trisaccharides (Neu5Ac $(\alpha 2-8) \mathrm{Neu} 5 \mathrm{Ac}(\alpha 2-3) \mathrm{Gal})$, illustrating the important role that the entire substrate molecule plays in the recognition process [21]. Crystallization of the $A$. fumigatus sialidase and structural analysis will likely provide more information regarding substrate recognition and catalytic mechanism. Alternatively, the decreased activity may be due to a lack of proper posttranslational modification due to the expression of the eukaryotic $A$. fumigatus sialidase in bacteria. There is a potential, albeit low scoring, N-glycosylation site at Asn 215; glycosylation at this site may be important for proper enzyme folding and function. No N-glycosylation has been detected in the human cytosolic sialidase, Neu2 [37]; however, elimination of glycosylation at one of the four glycosylation sites in the neuraminidase from the Newcastle disease virus was found to significantly decrease neuraminidase activity and this corresponded to a decreased virulence of the virus [40]. Finally, bacterial sialidases have an important role in nutrition by supplying the bacterium with both carbon and nitrogen. Because we have shown that $A$. fumigatus cannot use sialic acid as a sole source of carbon, the sialidase is likely to play a more important role in removal of terminal sialic acid from glycoproteins and glycolipids.

Sialidases have been isolated and characterized from a wide variety of eukaryotes and prokaryotes. As far as we are aware, sialidase activity of cells or culture filtrates has been reported for only a handful of fungi including Sporothrix schenckii [57] and its teleomorph, Ophiostoma stenocera [44], as well as Fonsecaea pedrosoi [4]. Saito and $\mathrm{Yu}$ [47] summarized the characteristics of microbial sialidases and included fungal sialidases in the title; however, no true fungi were included in their study. Another study indicated that Candida albicans possessed sialidase activity [46]; however, this was later refuted by others [44]. In support of this, we did not identify a sialidase gene in the $C$. albicans genome in our study. Unfortunately, genome sequences for Ophiostoma sternocera and Fonsecaea pedrosoi are not yet available so we could not include these in our phylogenetic analysis. In our study, fungal sialidases form a unique cluster more closely related to a subset of prokaryotic sialidases than to enzymes from other eukaryotes. Furthermore, sialidases were only detected in a few fungi from diverse lineages suggesting that these genes were acquired horizontally or have been lost from, or changed significantly in, all but a few ascomycete fungi. A possible bacterial origin of the fungal sialidases is suggested by our analyses; while the majority of $A$. fumigatus genes (77\%) contain introns with an average of 1.8 per gene [18], the A. fumigatus sialidase does not contain any introns; the mean difference in codon usage between the fungal sialidase and other A. fumigatus genes was greater than the difference between the sialidase codon usage and all S. avermitilis genes ( $24.3 \%$ versus $10.4 \%$, respectively). The $\% \mathrm{G}+\mathrm{C}$ value of the $A$. fumigatus sialidase $(64.7 \%)$ was intermediate between the average $\% \mathrm{G}+\mathrm{C}$ for A. fumigatus exons (54\%) and the average for streptomycetes (approximately 70\%). Finally, the Actinobacteria and the fungi that contain sialidase share similar habitats, which 
increase the possibility of gene transfer; all are filamentous, soil-dwelling saprobes that secrete hydrolytic enzymes to break down naturally-occurring polymers as a source of carbon and energy. Nevertheless, these data do not rule out the possibility that the gene was acquired by a common ancestor of the Pezizomycotina (which includes all of the fungal species with putative sialidases) [16] but then retained in only a few species.

Sialidase expression in A. fumigatus was upregulated during germination in MEM containing 10\% human serum. Using microarray analysis, we have found that serum exposure induces stress response genes (unpublished data) and mediators of the stress response may activate $A$. fumigatus gene expression through the STRE motif or via other uncharacterized mechanisms. Alternatively, sialidase expression may be developmentally regulated in A. fumigatus.

The role of the A. fumigatus sialidase in the life cycle of the fungus or in pathogenesis is currently unclear. Recently, we have shown that $\alpha 2$-6-linked unsubstituted sialic acids are present on the surface of A. fumigatus conidia and that these sugars play important roles in mediating the interaction between conidia and mouse macrophages and human type II epithelial cells, in vitro [60]. Despite their presence on the conidial surface, the mechanism of their biosynthesis and transport to the surface are unknown. In other microorganisms, several pathways have been elucidated for the biosynthesis of sialic acid and its display on the cell surface. For example, some bacteria have a complete biosynthetic pathway while others have only a few enzymes and rely on environmental sources for sialic acid or its precursors [58]. Even though our results indicate that sialic acid is synthesized de novo in A. fumigatus, work in our laboratory and by others [5, 55] has failed to identify orthologues of known sialic acid biosynthetic genes in the genomes of A. fumigatus and other fungi. The A. fumigatus genome does contain genes encoding several nucleotide-sugar transporters and glycosyltransferases, which together may function to sialylate the surface of A. fumigatus conidia. Furthermore, [43] have partially purified a sialyltransferase from another fungal pathogen, Cryptococcus neoformans although the gene has not yet been identified. Nevertheless, supplementation of growth media with sialic acid or $\mathrm{N}$ acetylmannosamine (a sialic acid precursor in other organisms) did not enhance sialic acid levels in $A$. fumigatus [55]. Alpha-2,3-linked sialic acids are undetectable in A. fumigatus [60,62] and the preference for this substrate suggests that the A. fumigatus sialidase is likely not involved in glycan remodelling.

Thus, sialic acid metabolism in fungi has many intriguing findings but the full picture of sialobiology in this Kingdom has yet to emerge.
Acknowledgements and funding We are grateful to Dr. Steve Withers for the kind gifts of bodipy-lactoside, bodipy-lactose-sialic acid and the recombinant T. cruzi trans-sialidase. We acknowledge Dr. Jamie Rich and Ms. Yuan Yao for their expert technical assistance with the trans-sialidase assay. This work was supported by the Natural Sciences and Engineering Research Council of Canada (MM and AB).

\section{References}

1. Achyuthan, K.E., Achyuthan, A.M.: Comparative enzymology, biochemistry and pathophysiology of human exo-alpha-sialidases (neuraminidases). Comp Biochem Physiol B. Biochem Mol Biol. 129, 29-64 (2001)

2. Aharoni, A., Thieme, K., Chiu, C.P., Buchini, S., Lairson, L.L., Chen, H., Strynadka, N.C., Wakarchuk, W.W., Withers, S.G.: High-throughput screening methodology for the directed evolution of glycosyltransferases. Nature Methods 8, 589-590 (2006)

3. Altschul, S.F., Madden, T.L., Schaffer, A.A., Zhang, J., Zhang, Z., Miller, W., Lipman, D.J.: Gapped BLAST and PSI-BLAST: a new generation of protein database search programs. Nucleic Acids Res. 25, 3389-3402 (1997)

4. Alviano, D.S., Rodrigues, M.L., Almeida, C.A., Santos, A.L., Couceiro, J.N., Soares, R.M., Travassos, L.R., Alviano, C.S.: Differential expression of sialylglycoconjugates and sialidase activity in distinct morphological stages of Fonsecaea pedrosoi. Arch Microbiol. 181, 278-288 (2004)

5. Angata, T., Varki, A.: Chemical diversity in the sialic acids and related alpha-keto acids: an evolutionary perspective. Chem Rev. 102, 439-469 (2002)

6. Bannai, H., Tamada, Y., Maruyama, O., Nakai, K., Miyano, S.: Extensive feature detection of $\mathrm{N}$-terminal protein sorting signals. Bioinformatics 18, 298-305 (2002)

7. Bendtsen, J.D., Nielsen, H., von Heijne, G., Brunak, S.: Improved prediction of signal peptides: SignalP 3.0. J Mol Biol 340, 783795 (2004)

8. Bennett-Lovsey, R.M., Herbert, A.D., Sternberg, M.J., Kelley, L. A.: Exploring the extremes of sequence/structure space with ensemble fold recognition in the program Phyre. Proteins 70, 611625 (2008)

9. Bradford, M.M.: A rapid and sensitive method for the quantitation of microgram quantities of protein utilizing the principle of protein-dye binding. Anal Biochem. 72, 248-254 (1976)

10. Burnaugh, A.M., Frantz, L.J., King, S.J.: Growth of Streptococcus pneumoniae on human glycoconjugates is dependent upon the sequential activity of bacterial exoglycosidases. J Bacteriol 190, 221-230 (2008)

11. Copley, R.R., Russell, R.B., Ponting, C.P.: Sialidase-like Asp-boxes: sequence-similar structures within different protein folds. Protein Sci. 10, 285-292 (2001)

12. Corfield, T.: Bacterial sialidases-roles in pathogenicity and nutrition. Glycobiology 2, 509-521 (1992)

13. Fedorova. N.D., Khaldi, N., Joardar, V.S., Maiti, R., Amedeo, P., Anderson, M.J., Crabtree, J., Silva, J.C., Badger, J.H., Albarraq, A., Angiuoli, S., Bussey, H., Bowyer, P., Cotty, P.J., Dyer, P.S., Egan, A., Galens, K., Fraser-Liggett, C.M., Haas, B.J., Inman, J. M., Kent, R., Lemieux, S., Malavazi, I., Orvis, J., Roemer, T., Ronning, C.M., Sundaram, J.P., Sutton, G., Turner, G., Venter, J. C., White, O.R., Whitty, B.R., Youngman, P., Wolfe, K.H., Goldman, G.H., Wortman, J.R., Jiang, B., Denning, D.W., Nierman, W.C. Genomic islands in the pathogenic filamentous fungus Aspergillus fumigatus. PLoS Genet 4. e1000046 (2008) 
14. Felsenstein, J.: Comparative methods with sampling error and within-species variation: contrasts revisited and revised. Am Nat 171, 713-725 (2008)

15. Feng, B., Xiao, X., Marzluf, G.A.: Recognition of specific nucleotide bases and cooperative DNA binding by the transacting nitrogen regulatory protein NIT2 of Neurospora crassa. Nucleic Acids Res. 21, 3989-3996 (1993)

16. Fitzpatrick, D.A., Logue, M.E., Stajich, J.E., Butler, G.: A fungal phylogeny based on 42 complete genomes derived from supertree and combined gene analysis. BMC Evol Biol. 6, 99 (2006)

17. Fuhrmann, M., Hausherr, A., Ferbitz, L., Schodl, T., Heitzer, M., Hegemann, P.: Monitoring dynamic expression of nuclear genes in Chlamydomonas reinhardtii by using a synthetic luciferase reporter gene. Plant Mol Biol 55, 869-881 (2004)

18. Galagan, J.E., Calvo, S.E., Cuomo, C., Ma, L.J., Wortman, J. R., Batzoglou, S., Lee, S.I., Basturkmen, M., Spevak, C.C., Clutterbuck, J., Kapitonov, V., Jurka, J., Scazzocchio, C., Farman, M., Butler, J., Purcell, S., Harris, S., Braus, G.H., Draht, O., Busch, S., D'Enfert, C., Bouchier, C., Goldman, G. H., Bell-Pedersen, D., Griffiths-Jones, S., Doonan, J.H., Yu, J., Vienken, K., Pain, A., Freitag, M., Selker, E.U., Archer, D.B., Penalva, M.A., Oakley, B.R., Momany, M., Tanaka, T., Kumagai, T., Asai, K., Machida, M., Nierman, W.C., Denning, D.W., Caddick, M., Hynes, M., Paoletti, M., Fischer, R., Miller, B., Dyer, P., Sachs, M.S., Osmani, S.A., Birren, B.W.: Sequencing of Aspergillus nidulans and comparative analysis with A. fumigatus and A. oryzae. Nature. 438, 1105-1115 (2005)

19. Galen, J.E., Ketley, J.M., Fasano, A., Richardson, S.H., Wasserman, S.S., Kaper, J.B.: Role of Vibrio cholerae neuraminidase in the function of cholera toxin. Infect Immun 60, 406-415 (1992)

20. Guex, N., Peitsch, M.C.: SWISS-MODEL and the SwissPdbViewer: an environment for comparative protein modeling. Electrophoresis 18, 2714-2723 (1997)

21. Ha, K.T., Lee, Y.C., Cho, S.H., Kim, J.K., Kim, C.H.: Molecular characterization of membrane type and ganglioside-specific sialidase (Neu3) expressed in E. coli. Mol Cells 17, 267-273 (2004)

22. Herbrecht, R., Denning, D.W., Patterson, T.F., Bennett, J.E., Greene, R.E., Oestmann, J.W., Kern, W.V., Marr, K.A., Ribaud, P., Lortholary, O., Sylvester, R., Rubin, R.H., Wingard, J.R., Stark, P., Durand, C., Caillot, D., Thiel, E., Chandrasekar, P.H., Hodges, M.R., Schlamm, H.T., Troke, P.F., de Pauw, B.: Invasive fungal infections group of the European Organisation for Research and Treatment of Cancer and the Global Aspergillus Study Group. N Engl. J Med. 347, 408-415 (2002)

23. Huson, D.H., Richter, D.C., Rausch, C., Dezulian, T., Franz, M., Rupp, R.: Dendroscope: an interactive viewer for large phylogenetic trees. BMC Bioinformatics 8, 460 (2007)

24. Ikeda, H., Ishikawa, J., Hanamoto, A., Shinose, M., Kikuchi, H., Shiba, T., Sakaki, Y., Hattori, M., Omura, S.: Complete genome sequence and comparative analysis of the industrial microorganism Streptomyces avermitilis. Nat Biotechnol 21, 526-531 (2003)

25. Indurugalla, D., Watson, J.N., Bennet, A.J.: Natural sialoside analogues for the determination of enzymatic rate constants. Org Biomol Chem. 4, 4453-4459 (2006)

26. Kishino, H., Hasegawa, M.: Evaluation of the maximum likelihood estimate of the evolutionary tree topologies from DNA sequence data, and the branching order in hominoidea. $\mathrm{J}$ Mol Evol. 29, 170-179 (1989)

27. Kolisis, F.N.: An immobilized bienzyme system for assay of sialic acid. Biotechnol Appl Biochem. 8, 148-152 (1986)

28. Kruse, S., Kleineidam, R.G., Roggentin, P., Schauer, R.: Expression and purification of a recombinant "small" sialidase from Clostridium perfringens A99. Protein Expr Purif. 7, 415-422 (1996)
29. Lang, B.F., O'Kelly, C., Nerad, T., Gray, M.W., Burger, G.: The closest unicellular relatives of animals. Curr Biol. 12, 1773-1778 (2002)

30. Latgé, J.P.: Aspergillus fumigatus and aspergillosis. Clin Microbiol Rev 12, 310-350 (1999)

31. Livak, K.J., Schmittgen, T.D.: Analysis of relative gene expression data using real-time quantitative PCR and the 2(-Delta Delta C(T)) method. Methods 25, 402-408 (2001)

32. Marr, K.A., Boeckh, M., Carter, R.A., Kim, H.W., Corey, L.: Combination antifungal therapy for invasive aspergillosis. Clin Infect Dis. 39, 797-802 (2004)

33. Matys, V., Fricke, E., Geffers, R., Gossling, E., Haubrock, M., Hehl, R., Hornischer, K., Karas, D., Kel, A.E., Kel-Margoulis, O. V., Kloos, D.U., Land, S., Lewicki-Potapov, B., Michael, H., Munch, R., Reuter, I., Rotert, S., Saxel, H., Scheer, M., Thiele, S., Wingender, E.: TRANSFAC: transcriptional regulation, from patterns to profiles. Nucleic Acids Res. 31, 374-378 (2003)

34. Minari, A., Husni, R., Avery, R.K., Longworth, D.L., DeCamp, M., Bertin, M., Schilz, R., Smedira, N., Haug, M.T., Mehta, A., Gordon, S.M.: The incidence of invasive aspergillosis among solid organ transplant recipients and implications for prophylaxis in lung transplants. Transpl Infect Dis. 4, 195-200 (2002)

35. Miyagi, T., Wada, T., Yamaguchi, K., Hata, K.: Sialidase and malignancy: a minireview. Glycoconj J. 20, 189-198 (2004)

36. Monti, E., Bassi, M.T., Papini, N., Riboni, M., Manzoni, M., Venerando, B., Croci, G., Preti, A., Ballabio, A., Tettamanti, G., Borsani, G.: Identification and expression of NEU3, a novel human sialidase associated to the plasma membrane. Biochem $\mathrm{J}$. 349, 343-351 (2000)

37. Monti, E., Preti, A., Nesti, C., Ballabio, A., Borsani, G. Expression of a novel human sialidase encoded by the NEU2 gene. Glycobiology. 9, 1313-1321 (1999)

38. Morgan, J., Wannemuehler, K.A., Marr, K.A., Hadley, S., Kontoyiannis, D.P., Walsh, T.J., Fridkin, S.K., Pappas, P.G., Warnock, D.W.: Incidence of invasive aspergillosis following hematopoietic stem cell and solid organ transplantation: interim results of a prospective multicenter surveillance program. Med Mycol. 43(Suppl 1), S49-58 (2005)

39. Pagano, L., Caira, M., Candoni, A., Offidani, M., Fianchi, L., Martino, B., Pastore, D., Picardi, M., Bonini, A., Chierichini, A., Fanci, R., Caramatti, C., Invernizzi, R., Mattei, D., Mitra, M.E., Melillo, L., Aversa, F., Van Lint, M.T., Falcucci, P., Valentini, C. G., Girmenia, C., Nosari, A.: The epidemiology of fungal infections in patients with hematologic malignancies: the SEIFEM-2004 study. Haematologica. 91, 1068-1075 (2006)

40. Panda, A., Elankumaran, S., Krishnamurthy, S., Huang, Z., Samal, S.K.: Loss of N-linked glycosylation from the hemagglutininneuraminidase protein alters virulence of Newcastle disease virus. J Virol. 78, 4965-4975 (2004)

41. Peterbauer, C.K., Litscher, D., Kubicek, C.P.: The Trichoderma atroviride seb1 (stress response element binding) gene encodes an AGGGG-binding protein which is involved in the response to high osmolarity stress. Mol Genet Genomics. 268, 223-231 (2002)

42. Potier, M., Mameli, L., Belisle, M., Dallaire, L., Melancon, S. B.: Fluorometric assay of neuraminidase with a sodium (4methylumbelliferyl-alpha-D-N-acetylneuraminate) substrate. Anal Biochem 94, 287-296 (1979)

43. Rodrigues, M.L., Dobroff, A.S., Couceiro, J.N., Alviano, C.S., Schauer, R., Travassos, L.R.: Sialoglycoconjugates and sialyltransferase activity in the fungus Cryptococcus neoformans. Glycoconj J 19, 165-173 (2003)

44. Roggentin, P., Krug, G., Schauer, R., Brasch, J.: Lack of sialidase activity in Candida albicans and Candida glabrata. Mycoses. 42, 33-36 (1999) 
45. Roggentin, P., Rothe, B., Kaper, J.B., Galen, J., Lawrisuk, L., Vimr, E.R., Schauer, R.: Conserved sequences in bacterial and viral sialidases. Glycoconj J. 6, 349-353 (1989)

46. Royal Jr., G.C., Nandedkar, A.K., Sampson, C.C., Faggett, T.: Neuraminidase production by Candida albicans. J Natl Med Assoc. 76, 143-145 (1984)

47. Saito, M., Yu, R.K.: Biochemistry and function of sialidases. In: Rosenberg, A. (ed.) Biology of the sialic acids, pp. 261-314. Plenum, New York (1995)

48. Sambrook, J., Fritsch, E.F., Maniatis, T.: Molecular cloning: A laboratory manual, 2nd edn. Cold Spring Harbor Laboratory, Cold Spring Harbor (1989)

49. Sato, K., Miyagi, T.: Involvement of an endogenous sialidase in skeletal muscle cell differentiation. Biochem Biophys Res Commun. 221, 826-830 (1996)

50. Segal, L., Lapidot, M., Solan, Z., Ruppin, E., Pilpel, Y., Horn, D.: Nucleotide variation of regulatory motifs may lead to distinct expression patterns. Bioinformatics. 23, i440-449 (2007)

51. Shelton, B.G., Kirkland, K.H., Flanders, W.D., Morris, G.K.: Profiles of airborne fungi in buildings and outdoor environments in the United States. Appl Environ Microbiol. 68, 1743-1753 (2002)

52. Simpson, H., Chusney, G.D., Crook, M.A., Pickup, J.C.: Serum sialic acid enzymatic assay based on microtitre plates: application for measuring capillary serum sialic acid concentrations. $\mathrm{Br} \mathrm{J}$ Biomed Sci. 50, 164-167 (1993)

53. Soong, G., Muir, A., Gomez, M.I., Waks, J., Reddy, B., Planet, P., Singh, P.K., Kaneko, Y., Wolfgang, M.C., Hsiao, Y.S., Tong, L., Prince, A.: Bacterial neuraminidase facilitates mucosal infection by participating in biofilm production. J Clin Invest. 116, 22972305 (2006)

54. Suzuki, Y.: Sialobiology of influenza: molecular mechanism of host range variation of influenza viruses. Biol Pharm Bull. 28, 399-408 (2005)
55. Tiralongo, J., Wohlschlager, T., Tiralongo, E., Kiefel, M.J.: Inhibition of Aspergillus fumigatus conidia binding to extracellular matrix proteins by sialic acids: a pH effect? Microbiology 155, 3100-3109 (2009)

56. Tringali, C., Papini, N., Fusi, P., Croci G., Borsani G., Preti, A., Tortora, P., Tettamanti, G., Venerando, B., Monti, E.: Properties of recombinant human cytosolic sialidase HsNEU2. J Biol Chem. 279, 3169-3179 (2004)

57. Uchida, Y., Tsukada, Y., Sugimori, T.: Production of microbial neuraminidases induced by colominic acid. Biochim Biophys Acta. 350, 425-431 (1974)

58. Vimr, E.R., Kalivoda, K.A., Deszo, E.L., Steenbergen, S.M.: Diversity of microbial sialic acid metabolism. Microbiol Mol Biol Rev. 68, 132-153 (2004)

59. Wainright, P.O., Hinkle, G., Sogin, M.L., Stickel, S.K.: Monophyletic origins of the metazoa: an evolutionary link with fungi. Science. 260, 340-342 (1993)

60. Warwas, M.L., Watson, J.N., Bennet, A.J., Moore, M.M.: Structure and role of sialic acids on the surface of Aspergillus fumigatus conidiospores. Glycobiology 17, 401-410 (2007)

61. Wasylnka, J.A., Moore, M.M.: Adhesion of Aspergillus species to extracellular matrix proteins: evidence for involvement of negatively charged carbohydrates on the conidial surface. Infect Immun. 68, 3377-3384 (2000)

62. Wasylnka, J.A., Simmer, M.I., Moore, M.M.: Differences in sialic acid density in pathogenic and non-pathogenic Aspergillus species. Microbiology 147, 869-877 (2001)

63. Winkelstein, J.A., Marino, M.C., Johnston Jr., R.B., Boyle, J., Curnutte, J., Gallin, J.I., Malech, H.L., Holland, S.M., Ochs, H., Quie, P., Buckley, R.H., Foster, C.B., Chanock, S.J., Dickler, H.: Chronic granulomatous disease. Report on a national registry of 368 patients. Medicine (Baltimore) 79, $155-169$ (2000) 